\title{
Force Measurement and Design of a Torquing Highpull Headgear
}

John William Tabash

Loyola University Chicago

Follow this and additional works at: https://ecommons.luc.edu/luc_theses

Part of the Orthodontics and Orthodontology Commons

\section{Recommended Citation}

Tabash, John William, "Force Measurement and Design of a Torquing Highpull Headgear" (1983). Master's Theses. 3278.

https://ecommons.luc.edu/luc_theses/3278

This Thesis is brought to you for free and open access by the Theses and Dissertations at Loyola eCommons. It has been accepted for inclusion in Master's Theses by an authorized administrator of Loyola eCommons. For more information, please contact ecommons@luc.edu. c) (i) ()

This work is licensed under a Creative Commons Attribution-Noncommercial-No Derivative Works 3.0 License. Copyright (c) 1983 John William Tabash 
FORCE MEASUREMENT AND DESIGN

OF A

TORQUING HIGHPULL HEADGEAR

by

John William Tabash, D.D.S.

A Thesis Submitted to the Faculty of the Graduate School of Loyola University of Chicago in Partial Fulfillment of the Requirements for the Degree of

Master of Science

March

1983 
(C) 1983, John William Tabash 


\section{DEDICATION}

To my parents, Dr. John and Catherine

Tabash, for their sacrifices throughout

my education and for their inspiration. 


\section{ACKNOWLEDGMENTS}

My deepest appreciation is extended to all those who have aided in making this study possible. A special note of gratitude must be acknowledged to the following people:

To James L. Sandrik, Ph.D., whose knowledge and assistance guided me through the research;

To Douglas Bowman, Ph.D., whose knowledge in statistics was invaluable to the completion of this project;

To Lewis Klapper, D.M.D., M.Sc., D.Sc., who has guided me not only through this research but also my orthodontic education;

To Richard L. Lang, D.D.S., M.S., whose knowledge along with many hours of unselfish assistance, enthusiasm, and patience aided me in the completion of this research.

To Mr. Nick DiCarlo, Mr. Mike Ekinaka and Mr. Tony Iverson (Unitek), Mr. George Muros and Mr. Lee Tuneberg (American), and Mr. Michael Schechter (GAC) for their assistance in providing the materials and information for this thesis;

To Mr. James Cockerill for his assistance with the photography necessary for this work;

To Mrs. Bobbi Schaff for her generous contribution of time and effort in typing this paper.

A very special thank you is extended to Efstathios Marinakis, D.D.S., former faculty member in the Department of Orthodontics at 
Loyola University for his great enthusiasm and love for teaching orthodontics to my classmates and me. 


\section{VITA}

John William Tabash was born on August 17, 1955, the second of four children to John and Catherine (Meyer) Tabash in St. Louis, Missouri. His elementary education was obtained at Our Lady of Providence Catholic School in St. Louis, Missouri and secondary education at St. John Vianney High School in St. Louis, where he graduated in May 1973.

In September 1973, he entered Tulsa University in Tulsa, Oklahoma where he remained until June of 1974. In August 1974, he transferred and enrolled at University of Missouri-Columbia in Columbia, Missouri and was graduated in May 1977 with a Bachelor of Arts degree in Biology. In the same year, he began his dental education at University of MissouriKansas City School of Dentistry, Kansas City, Missouri. He received his Doctor of Dental Surgery degree in May 1981.

In July 1981, he entered Loyola University in the Graduate School of Oral Biology and in the Postgraduate program in Orthodontics. 
PAGE

DEDICATION....................... . . . ACKNOWLEDGMENTS . . . . . . . . . . . . . . . . i i VITA. . . . . . . . . . . . . .... v v LIST OF TABLES. . . . . . . . . . . . . . . . . viij LIST OF ILLUSTRATIONS . . . . . . . . . . . . . . . . . ix CONTENTS OF APPENDICES. . . . . . . . . . . . . . $\quad x$ Chapter

I. INTRODUCTION . . . . . . . . . . . . . 1

II. REVIEW OF LITERATURE . . . . . . . . . . . . 6

III. MATERIALS AND METHODS. . . . . . . . . . . . 31

IV. RESULTS.................... 40

V. DISCUSSION . . . . . . . . . . . . . . 53

VI. SUMMARY. . . . . . . . . . . . . . 58

VII. CONCLUSION . . . . . . . . . . . . . . . . . 60

VIII. BIBLIOGRAPHY . . . . . . . . . . . . . 61 Appendix A-1 ............................. 67

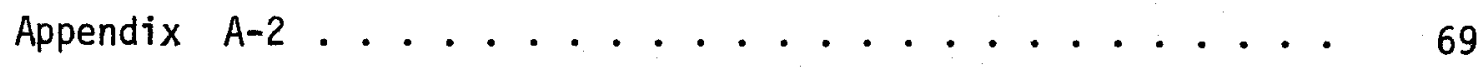
Appendix A-3 ........................... 71 Appendix A-4 ........................... 73 Appendix A-5 ......................... 75 Appendix A-6 . . . . . . . . . . . . . . 77 Appendix A-7 . . . . . . . . . . . . . . 79 
PAGE

Appendix A-8 ........................... 81

Appendix A-9 .................. 83

Appendix A-10.................... 85

Appendix A-11 . . . . . . . . . . . . 87

Appendix A-12................. 89

Appendix A-13 . . . . . . . . . . . . . . 91

Appendix A-14................... 93 


\section{LIST OF TABLES}

Table

Page

I Distal tipping of maxillary first molars with cervical traction facebows. . ...............

II Distal tipping of maxillary first molars with highpull

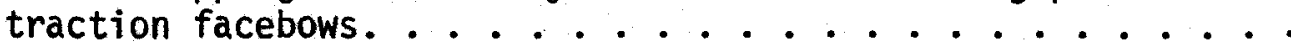

III Means, standard deviations, and 95\% confidence measurements of cervical and highpull traction facebow readings, as well as a t-comparison between the first and second measurements. .

IV T-comparison of cervical traction facebow readings versus highpull traction facebow readings ...........

$\checkmark$ Average distance and specific force readings that elastics were stretched from outer bows of torqued and non-torqued facebows to vertical post of the DEFA. . . . . . . .

VI Mean and standard deviations for buccal tipping and transverse translation of maxillary right and left molar of torqued and non-torqued facebows for various magnitudes of force. . . . . . . . . . . . .

VII T-comparisons of non-torqued facebows for various magnitudes of force for buccal tipping and transverse translation of maxillary right and left molar. . . . . . .

VIII T-comparisons of torqued facebows for various magnitudes of force for buccal tipping and transverse translation of maxillary right and left molar. . . . . . . . . . .

IX T-comparisons of torqued vs. non-torqued facebows for various magnitudes of force for buccal tipping and transverse translation of maxillary right and left molar...

$X$ T-comparisons of torqued vs. non-torqued facebows for various magnitudes of force for buccal tipping and transverse translation of maxillary right and left molar. . . 


\section{LIST OF ILLUSTRATIONS}

Figure

Page

1. Location of the center of resistance of maxillary

first molar. .................

2. Moment produced in the sagittal plane dependent on the position of the outer bow of four facebows ........

3. Moment produced in the sagittal plane dependent on the position of the outer bow of four facebows . . . . . . .

4. Perpendicular distance of the force vector to the center of resistance causing rotation of the molar. . . . . .

5. Center of rotation approaches infinity causing translation of the molar ...............

6. Movement of maxillary molar with the use of a highpull headgear.

7. Universal plier and doubled over distal end of inner bow of facebow .................

8. Overall view of the Dynamic Extraoral Force Analyzer (DEFA).......................

9. Suspension of maxillary molar by four diagonally arranged springs, cross-like indicator coupled with and centered over each buccal tube, and fulcrum of the suspended molars is marked on the root portion with a metallic point. . . .

10. Unit grid interposed between the buccal tube and crosslike indicator

11. Unit grid adapted distal to the vertical arm of the

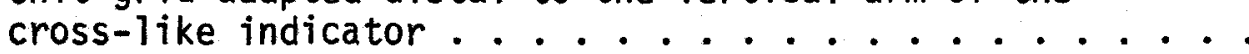

12. Dial Gauge Caliper measuring elastic stretch from outer bow to horizontal sliding bar. 
Appendix A-1 Distance of stretch of two ounce elastics on non-torqued facebows. ..........

Appendix A-2 Distance of stretch of four ounce elastics on non-torqued facebows. ..........

Appendix A-3 Distance of stretch of six ounce elastics on non-torqued facebows. . . . . . . . . .

Appendix A-4 Distance of stretch of two ounce elastics on torqued facebows........... 73

Appendix A-5 Distance of stretch of four ounce elastics on torqued facebows........... 75

Appendix A-6 Distance of stretch of six ounce elastics on torqued facebows. . ..........

Appendix A-7 Units of tooth movements with facebows of zero torque and two ounce elastics ........

Appendix A-8 Units of tooth movements with facebows of zero torque and four ounce elastics. . . . . .

Appendix A-9 Units of tooth movements with facebows of zero torque and six ounce elastics .......

Appendix A-10 Units of tooth movements with facebows of nine degrees of torque and two ounce elastics. .

Appendix A-11 Units of tooth movements with facebows of nine degrees of torque and four ounce elastics..

Appendix A-12 Units of tooth movements with facebows of nine degrees of torque and six ounce elastics. .

Appendix A-13 T-comparisons of non-torqued facebows for various magnitudes of force for buccal and distal tipping, anterior-posterior, and transverse translation of maxillary right and left molar.................. 
Appendix A-14 T-comparisons of torqued facebows for various magnitudes of force for buccal and distal tipping, anterior-posterior and transverse translation of maxillary right and left molar. ........... 


\section{CHAPTER I}

\section{INTRODUCTION}

A common problem in orthodontics is vertical control of the dolycocephalic (i.e. vertical growing, backward rotating) facial pattern. In this type of patient, the objective is to retard both the vertical eruption of the maxillary molars and the descent of the maxilla. This is commonly accomplished through the use of a headgear with the vector of force directed towards the parietal region (Hilgers et al., 1972).

Headgear is an extraoral appliance which directs forces from the extraoral region to the intraoral region through the use of a large gauge round wire connected to the maxillary first molars by way of close fitting round tubes attached to the molars. Highpull headgear specifically directs force towards the parietal area (i.e. upwards and backwards). From a biomechanical standpoint, the round wire of the highpull headgear creates the problem of a tipping or "rolling" effect of the maxillary molar crown to the buccal with concomitant root movement lingually (Merrifield and Cross, 1970; Armstrong, 1971; Hickman, 1974; Berman, 1976). This movement has been shown to be prevented through the placement of a transpalatal bar. Properly adjusted, the transpalatal bar could effectively create transverse bodily movement when used in conjunction with extraoral parietal traction (Jacobsen, 1979). 
Translation (i.e. bodily movement of crown and root simultaneously) of the molar without the use of the transpalatal bar can only be achieved when the round wire of the facebow is substituted for with square, rectangular, ovoid, or doubled over round wire placed in close fitting buccal tubes of similar shape attached to the molars using parietal traction (Jacobsen, 1979).

Although many investigators have studied the torquing moment to molar teeth created by third order archwire bends (torque in rectangular wire) and/or auxilliaries (Angle, 1929; Creekmore, 1979), there remains a scarcity of research concerning the torquing capabilities of a single extraoral appliance which would achieve the desired result simply and within optimum biologic conditions.

Optimum orthodontic force is that which produces a maximum desireable biologic response with minimum tissue damage, resulting in rapid tooth movement with little or no clinical discomfort (Nickolai, 1975; Storey and Smith, 1952). The optimum force needed for transverse movement of the maxillary first molar varies from 135-205 grams (Lee, 1979). A device exists (Dynamic Extraoral Force Analyzer or DEFA, by Unitek) which is said to be capable of measuring linear deflection as a function of force created by a headgear (Rusch and Stockli, 1970).

The three main steps (Contasti and Legan, 1982) needed to design a headgear to deliver the desired force system are:

1.) Locate the center of resistance (CR) of an object to which the force is to be applied. The object is the maxillary first molar. 
$C R$ is that point of a constrained body through which a single force will cause translation of that body (Burstone, 1962). CR is located approximately at the trifurcation of the maxillary molar in the region of the middle to apical third of the root (Greenspan, 1970; and Worms, 1973).

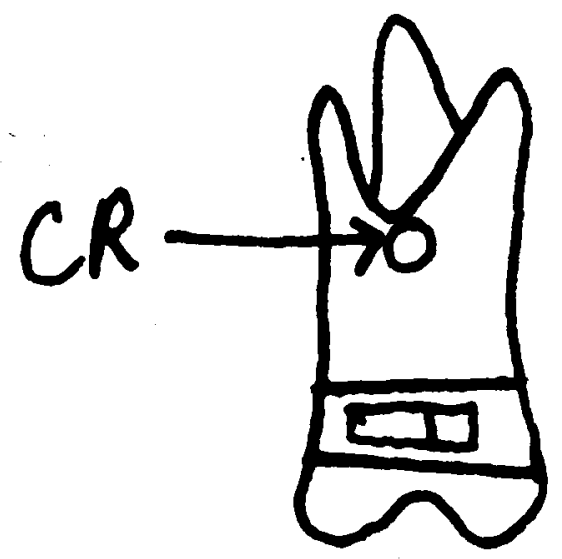

Figure 1. Location of the center of resistance of the maxillary first molar. CR-center of resistance.

2.) Construct the "zero moment line of force" (LFO) based on the direction of force. When the line of force (LF) is applied through the CR no tipping will occur (Contasti and Legan, 1982).

3) Based on the desired direction and magnitude of the moment, position the outer bow relative to the LFO.

Highpull headgear produces a posterior and intrusive direction of force. The direction of the moment that is produced in the sagittal plane is dependent on the position of the outer bow (Gould, 1957). 


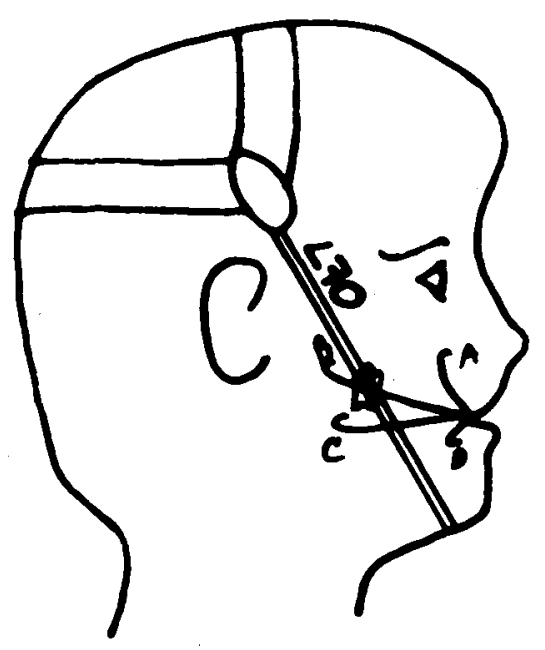

Figure 2. Moment produced in the sagittal plane dependent on the position of the outer bow. A,B,C, and D-outer bow of facebows. LFO - zero moment line of force.

Locating the outer bow in front of the LFO ( $A$ and $D$ ) will produce a counter-clockwise moment; while an outer bow behind ( $B$ and $C$ ) will create a clockwise moment. An outer bow located on LFO will produce no moment, which is the desired result (Christiansen and Burstone, 1969). However, the vertical position of the outer bow does not influence movement in the transverse plane.

As stated previously, the intrusive force of the highpull headgear will cause the maxillary molar crowns to tip or "roll" buccally, with concomitant root movement lingually (Armstrong, 1971; Merrifield and Cross, 1970; Hickman, 1974; Berman, 1976).

This study addresses the problem of buccal translation of maxillary 
molar teeth using a single extraoral appliance. Specifically the purpose of this research is to determine the capability of the DEFA to measure linear deflection as a function of force created by a headgear. This instrument will be used to determine whether a design modification, which will be proposed, is capable of retarding the buccal tipping or "rolling" effect on the maxillary molar crown created by the highpull headgear. The capability of the DEFA will be studied by determining the optimal forces generated by a torquing highpull headgear, and to suggest a design that would preclude buccal tipping of maxillary molar crowns. 


\section{REVIEW OF LITERATURE}

Angle (1928) discussed balance of the dentition, and emphasized the need for fully normal upright axial positions and relations of the crowns and roots of the teeth, if the teeth are to balance with the muscles, and sustain and maintain the great weight of occlusion.

Angle (1929) emphasized the fact in the correction of malocclusion ... "the teeth (both crowns and roots) should be moved directly and continuously from their malpositions into their correct positions without change in direction or more interruption of movement than is absolutely necessary .... force for the purpose of being firm, positive, steady, and continuous."

An appliance used in accomplishing orthodontic tooth movement is through the implementation of extraoral force. The use of extraoral forces began in the early 1800's when Cellier developed cervical and occipital traction to prevent luxation of the mandible.

Kingsley (1855) originally designed and described an occipital "headcap" to aid in retraction of the maxillary anterior teeth. The concept of extraoral force, of using an area outside the mouth as a base for anchorage is not new. Angle (1887) remarked:

"The value of the occipital bandage is, I believe, becoming more and more appreciated, and is especialiy applicable in this class of cases (maxillary protrusions). I am using the appliance in my sixteenth case, and I consider it much more satisfactory than any of the few devices described in our literature on the subject." 
Angle (1887) described his extraoral attachment. A long pin was soldered onto the $E$ arch at the midline, which rested on the central incisor bands where cleats were attached. The use of this appliance was limited to maxillary dental protrusion in patients following upper first bicuspid extractions.

Goddard (1888) had described the making of a vulcanite casing for molding black rubber against the maxillary anterior teeth to which was attached headcaps of dress hooks, with rubber elastic bands.

Guilford (1898) discussed directional pull by activating rubber strands of the "skullcap" above or below the ear.

Thus, up through the turn of the century, extraoral force was a major source of retraction of protrusive incisors. However, no enlightment was offered for molar corrections.

At the turn of the century the use of extraoral force fell into disfavor. It was not until Oppenheim (1911) showed that through the use of extraoral appliances an optimal force could be delivered to a tooth to produce rapid movement. The concept of optimal force developed when Oppenheim assumed that the periodontal ligament was essentially a hydrostatic system maintained by blood pressure of the capillary bed.

With the movement of teeth produced through the use of extraoral appliances; Fish (1917) pointed out that orthodontists cannot afford to construct and operate extraoral mechanical appliances with their customary disregard of the law of physics. Fish stated there are two kinds of motion; translation and rotation. Pure translation is a change in position, or bodily movement, of an object (tooth) without any change in 
direction of any of the axes or lines of the object (tooth). Fish concluded in stating until all orthodontists outgrow the use of intermediate extraoral appliances, and borrow from engineering the practice of laying out on paper what they propose to do before they try to do it, then the design of extraoral appliances in orthodontia will continue to be purely experimental.

Case (1921) had extented the application of extraoral therapy. Case described a type of extraoral application with the first solid mention of maxillary molars to be moved distally.

Strang (1935) discussed tipping of maxillary molars in regard to headgear wear. He stated: "that the mere tipping distally of the tooth crowns is not sufficient, but crown and root movement, coincidentally, is the factor that alone will meet the new requirement of correct axial position and stability of the maxillary molar."

Oppenehim (1936) following Strang's remarks, encouraged the use of headgear therapy in conjunction with orthodontic therapy to aid in the correct axial position and stability of the molar. Oppenehim placed molar bands and a dental bow all the way to the maxillary molars and applied a headcap.

Kloehn (1947) reported on an occipital headgear, which he later modified by soldering the outer and inner bows, creating the now popular Kloehn facebow.

In the early $1950^{\prime} s$, Shudy and others recognized undesireable rotation of the mandible in a downward and backward direction because of extrusion of the maxillary molars. At this time an anti-Kloehn movement 
took place. In order to encourage forward chin behavior, the neckstrap was replaced by an upward pull above the ear. This helped intrude the molar.

Gould (1957) following the mechanical engineering principles established by Fish (1917), and further explaining the vector of pull above the ear as shown by Shudy, emphasized the importance of the center of resistance of a tooth. Gould stated the exact center of resistance is unknown, but is generally assumed to be in the region of the middle to apical third of the root. Further discussion on the center of resistance provoked Gould to experiment and show a force which passes through the center of resistance will produce pure translation of a free body. However, if the force vector does not pass through the center of resistance, a moment arm is created with rotation resulting.

Taking advantage of Gould's engineering principles and concepts of treatment, Shudy along with Ricketts (1957) and Poulton (1959) designed a highpull molar headgear with the outer bow terminating at the sight of the center of resistance (middle to apical third of the root) of the maxillary first molar. They used this type of headgear in cases where they did not want to extrude the molars, such as in cases of high mandibular plane angles and open bites, thus allowing the mandible to assume a more forward position.

Graber (1957) further emphasized the importance of not extruding the maxillary molars in high mandibular plane angle cases by saying: "You cannot open a bite in a high mandibular plane angle case through extrusion of the molar and expect any stability." 
The use of extraoral treatment to bring about the bodily posterior movement of maxillary first molars was shown by Newcomb (1958). He further developed the idea that by initiating an upward and backward force vector through the use of a highpull headgear can bring about a cessation of the usual downward and forward migration of the maxillary molar.

Ricketts (1960) followed up Newcomb's work and suggested extraoral traction worn 12-14 hours per 24 hours will bodily move maxillary molars distally.

Burstone (1962) discusses the biomechanics of bodily movement of the maxillary molar not as Newcomb and Ricketts have with distal bodily movement using cervical traction, but rather bodily movement using highpull traction. His discussion involved force systems acting on a headgear tube in a maxillary molar. He showed an intrusive directed force from a highpull headgear on the buccal surface of the maxillary molar will tend to roll the crown buccally. However, if a clockwise moment (buccal root torque) is added of sufficient magnitude (either through the use of a palatal bar or torque incorporated into the inner facebow), the center of rotation moves towards the apex of the root. If an additional moment in the same direction is placed on the tooth, the center of rotation moves towards infinity and at this instance the tooth is translated.

Extrusion and intrusion of maxillary molars was further emphasized by Shudy $(1964,1965)$ in regards to its effect on facial esthetics. His work has given us an insight into the mechanism of the rotation of the 
mandible. He contends that: 1. Orthodontists should investigate ways of inhibiting vertical growth of the jaws in high angle cases. Shudy stressed molar elongation must be avoided in persons with retrognathic facile profiles, since extrusion of the posterior teeth tend to rotate the mandible dorsally, thereby aggravating their facial disfigurement. In this type of patient a highpull headgear is needed to prevent the extrusion of the maxillary molar. 2. Molars of high angle cases are easy to extrude, and once extruded, remain so. 3. Molars should not be extruded in high angle cases. 4. Class II correction is more difficult in high mandibular plane angle cases. Shudy stated: "it is not the growth of the mandible per se which primarily determines its posture, but instead the vertical growth of the maxilla." Shudy concluded when facial morphology indicates that vertical growth has been excessive, try to inhibit the downward growth of the maxillary molars through the use of a highpull headgear with an intrusive and distal direction of force.

Bergersen (1966) further reported on persons with a high mandibular plane angle that there was no tendency for this angle to be reduced through growth. He agreed with many researchers before him that patients with high mandibular plane angles should be treated with a highpull headgear, which is different treatment from that emphasized for a person of an average or low mandibular plane angle.

Creekmore (1967) following the work of Shudy, Ricketts, and Bergersen further developed the concept of vertical growth of the maxilla and its detrimental effects on high angle cases. He took a variety of male and female patients in their growing stages with high mandibular plane 
angles, and children with average mandibular plane angles. Showing that high angle cases are more susceptible to vertical development than average faces, the high angle cases tended to become even higher unless he attached highpull headgear to these children which pulled up and back on the maxilla in the maxillary molar region to inhibit their growth in the vertical direction.

Poulton (1967) stated that extraoral force appliances should be selected according to the particular requirement of each case, taking into account the malocclusion and the facial type. He showed many cases that had a poor facial esthetic result because of the use of cervical headgear which extruded the maxillary molars and increased the mandibular plane angle; thus elongating the patients facial esthetics. One method of avoiding this unwanted effect is to use a highpull headgear and facebow to the maxillary molar. The results of his patients with a highpull headgear showed a retraction and intrusion of the maxillary molars, along with an improvement of facial esthetics.

Not only American, but also European orthodontists such as Stevenson (1967) showed a special effect can be achieved through the use of an extraoral appliance, such as a restraining force to the downward and forward development of the maxillary molars in the dento-alveolar region. This effect is achieved through the use of a highpull headgear which gives a distal and intrusive force to the maxillary molars.

The mechanical effect the highpull headgear has on the maxillary molars was emphasized by Kuhn (1968). He showed the position of the facebows outer arm relative to the center of resistance of the maxillary 
molar will effect the position of the center of rotation in a number of ways. The first factor is the position in the anterior-posterior plane, i.e. the outer arms are made to end mesial or distal to the center of resistance of the tooth. The second factor is the position of the outer bow in the vertical plane, i.e. the bow is made to lie apical or occlusal to the center of resistance of the tooth, for this also determines the direction in which the tooth rotates.

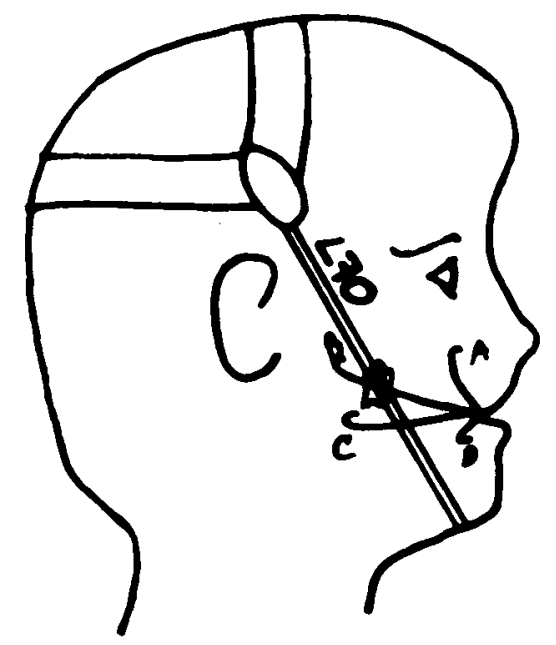

Figure 3. Moment produced in the sagittal plane dependent on the position of the outer bow. $A, B, C$, and $D$ - outer bows of facebows. LFO - zero moment line of force.

The highpull headgear produces posterior and intrusive forces. Locating the outer bow mesial to the LFO (zero moment line of force) (A and D) will produce a counter-clockwise moment; while an outer bow distal ( $B$ and $C$ ) will create a clockwise moment. An outer bow located on LFO will produce a moment. 
Christiansen (1969) further elaborated on the center of rotation concept by stating if the center of rotation is near the center or resistance, the body will predominantly rotate. Conversely, as the center of rotation approaches infinity, the body will predominately translate. Location of the center of rotation is inversely related to the perpendicular distance of the force vector to the center of resistance. As the perpendicular distance of the force vector to the center of resistance increases, the center of rotation approaches the center of resistance and vice versa. This is shown below:

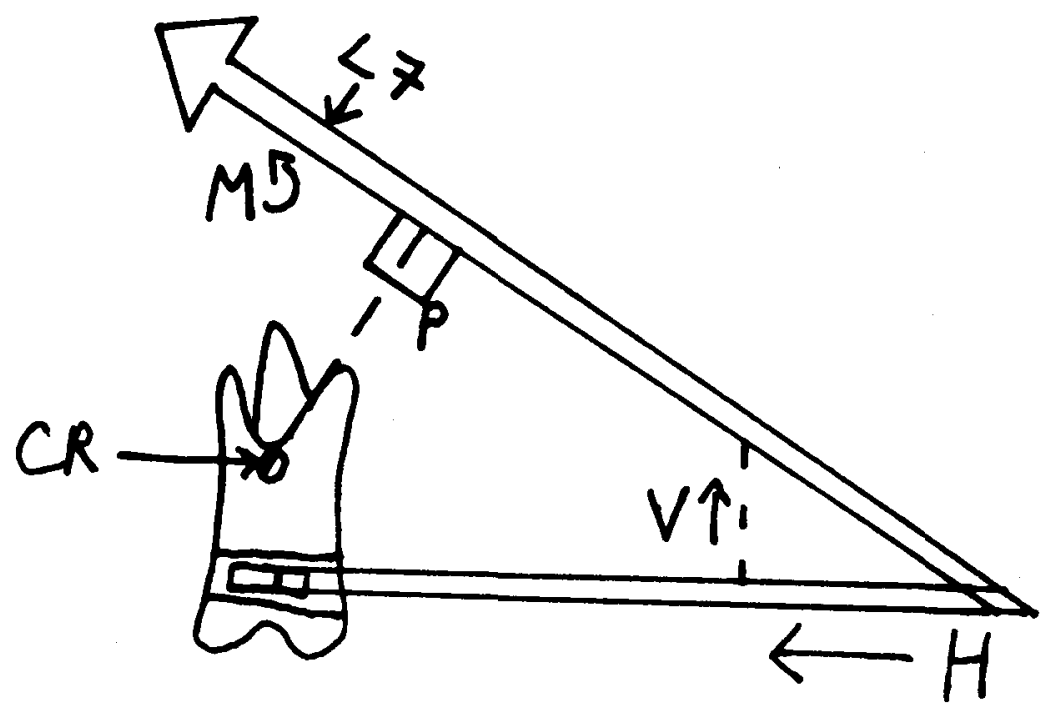

Figure 4. Perpendicular distance of the force vector to the center of resistance causing rotation of the maxillary molar. CR-center of resistance, M-moment produced on the maxillary molar, LF-line of force, P-perpendicular distance from CR to LF, V-vertical, H-horizontal.

Here the perpendicular distance of the force vector (distance from $C R$ to 
P) to the center of resistance (CR) increases, therefore the center of rotation approaches the center of resistance, and get rotation or tipping of the molar.

However in the diagram below there is no perpendicular distance of the force vector to the center of resistance, therefore the center of rotation approaches infinity and the body will transiate.

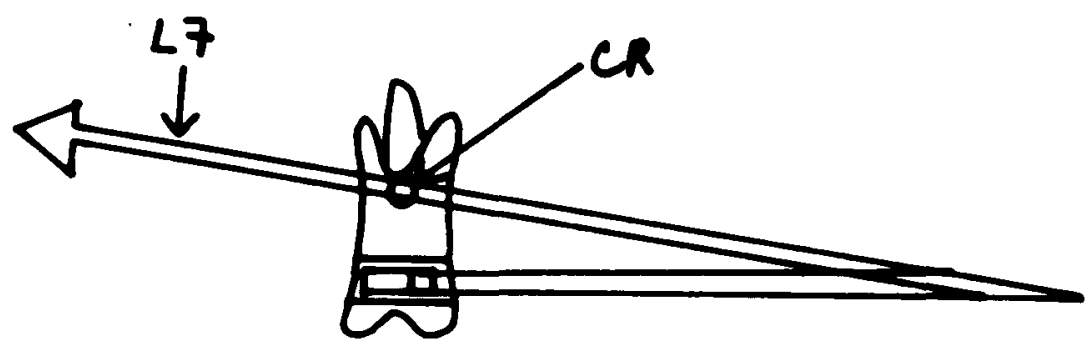

Figure 5. Center of rotation approaches infinity causing translation. CR-center of resistance, LF-line of force.

Greenspan (1970) believed monitoring of force systems according to biomechanical principles is a prerequisite to obtain controlled root movement. The direction in which molars will tip is a function of the position of the applied force in relation to the tooth's axis of rotation. The exact center of rotation of fulcrum of a tooth is unknown, but it is 
generally assumed to be at the middle to apical third of the root. Only a minimal amount of tipping occurs when the line of action of the applied force approximates the tooth's center of rotation. Tipping increases proportionately with the distance of this line to the center of rotation.

Greenspan went on further to illustrate a chart, indicating the movement of maxillary molars when a highpull headgear is used. Shown below is a copy of the chart.

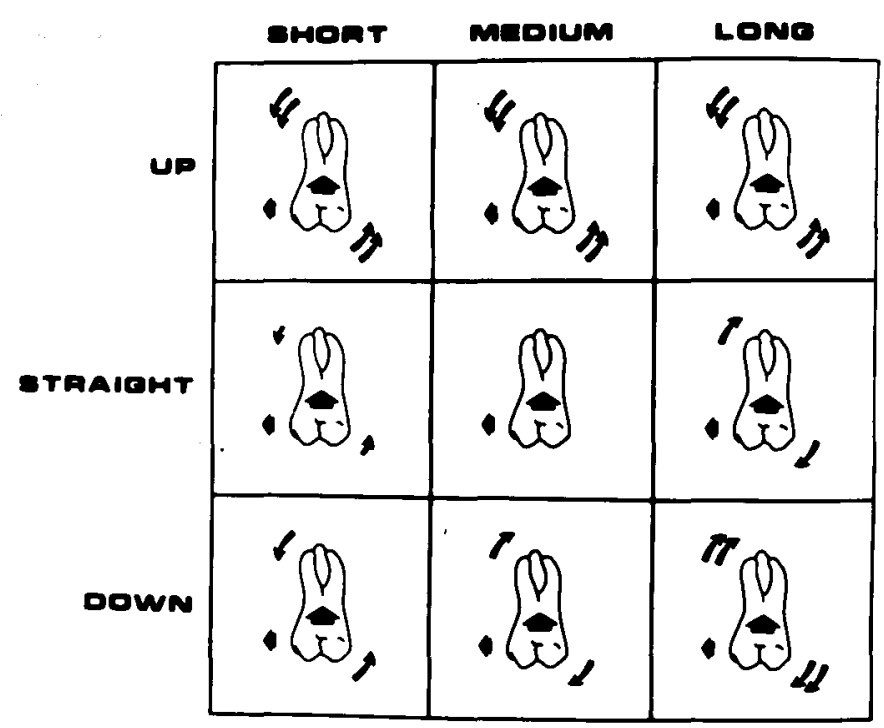

Figure 6 . Movement of the maxillary molar when highpull headgear is used. Courtesy of Greenspan, R.A.: "Reference charts for Controlled Extraoral Force Application to Maxillary Molars," American Journal of Orthodontics, 58:486-491, 1970.

In the chart above the direction of expected tooth movement is represented by straight arrows, and the most predominant movement in bold arrows. The amount of direction of tipping are indicated by curved 
arrows, their number and size being proportional to the extent of tipping movement transmitted to the permanent maxillary first molars. This will help to illustrate if an upward and backward force is desired with no tipping then a medium straight outer bow through the center of resistance is what is needed.

Merrifield and Cross (1970) along with Armstrong (1971), Hickman (1974) and Berman (1976) have all tested a direction of headgear pull to the maxillary arch upwards and backwards from the occlusal plane, such as that of a highpull headgear to the maxillary molars, will intrude the teeth closest to the attachment of the headgear. Along with this intrusive component they have all shown from a biomechanical standpoint, that the round wire of the highpull headgear creates the problem of a tipping or "rolling" effect of the maxillary molar crowns to the buccal with concomitant root movement lingually.

Rusch (1970) designed an instrument, the Dynamic Extraoral Force Analyzer (DEFA), which was used to study the effect of different arrangements of extraoral force, and the tipping and translation that occurred with highpull and cervical headgear.

The purpose and use of the highpull headgear was demonstrated by Hilgers, Nanda, Terrel, and Aytan (1971). They showed a highpull headgear delivers a force in a posterior-superior direction. They pointed out three basic purposes of its use: 1. Distalize or hold the maxillary first molar in its place. 2. Decrease the vertical dimension of the face by depressing the maxillary first molar and inhibit or redirect some of the sutural growth. 3. To correct Class II malocclusions. The 
researchers further emphasized the use of highpull headgear in patients with a high mandibular plane angle, high ANB discrepancy, open bite cases, and patients who have a deficient chin and/or gummy smile line.

Armstrong (1971) followed the work of Hilgers et al., in regard to extraoral application. He stated magnitude, direction, and duration are the three mechanical variables of extraoral force. He studied individual cases and showed for every different patient there is an optimum direction for the application of extraoral force for efficient and effective treatment. Armstrong further states the highpull headgear has a direction of pulf that is distal and intrusive. This is advantageous in treating a Class II case with a high mandibular plane angle, where it is important not to extrude the maxillary posterior teeth and is, in fact, advantageous to intrude them.

Barton (1972) suggested an upward and backward force, such as that of a highpull headgear, would exaggerate maxillary molar intrusion, while tipping their roots mesially. A rigid palatal arch must secure each molar to prevent the direction of pull from rolling them buccally.

Worms, Isaacson, and Speidel (1973) further researched the biomechanical effects of the extraoral force system. To effectively employ extraoral force systems it is necessary to consider not three as Armstrong said in 1971 , but rather four essentials. They are 1. centers of rotation. 2. direction. 3. magnitude. 4. duration.

Worms, et a1., went further on to describe the center of resistance and translation by showing when a force is applied to a body, the body resists the force. If all the separate resistances were analyzed, they 
would be directed to cause translation. This point of resistance in the dental system that promotes translation is called the center of resistance.

Worms et al., then raised the question of how then are forces directed through the center of resistance to cause translation? In order to translate, other vectors must be added to the force system. Two common methods are usually employed. One is to create a couple or moment, and the other is to adjust the cental attachment unit (bracket) by additional framework to the system (auxilliaries).

By adding sufficient couple to a force system (such as torque) that is not directed through the center of resistance, a proper ratio between the force and couple can be established to cause translation.

Pure translation requires a single force acting through the center of resistance, or a single force not through the center of resistance with a properly balanced couple.

Worms, et al., relate this concept to facebows by saying while the framework of the facebow has many designs and points of attachments to the tooth, the effect of the dental unit is ultimately only related to the shortest perpendicular distance between the force vector and the center of resistance. Therefore, the location of the headgear tube on the orthodontic band should make no difference in regards to the center of rotation of the maxillary molar.

Worms, et al., also stated in facebow design the less a facebow is deflected during activation, the more accurately the force type can be delivered to the tooth. They designed facebows with an inner bow diameter 
of .072 inch and .072 inch facebow tubes used for molar attachments. By increasing the inner bow to .072 inch from .045 inch, the stiffness of the wire increased fourfold. Thus the deflection during loading was only one-quarter as much as the .045 inner facebow, and the force delivered to the tooth was more accurate.

Oosthiezen, Dijkman and Evans (1973) emphasized line of action and the biomechanical effect of extraoral traction on the maxillary molar. They showed that when the line of action actually passes through the center of resistance of a maxillary first molar, then the perpendicular distance from the center of resistance to the line of action is zero. Therefore no tipping moment wi11 be present. They further demonstrated, in agreement with previous research in order to clinically manifest translation, the point of origin of the force, the hook of the outer bow, and the center of resistance of the maxillary molar must all be in the same straight line. Parietal traction has the origin of force well above the molar. They showed tipping can be controlled by a variation in the relationship of the inner and outer bows thus altering the inclination of the line of traction.

Harvold (1974) reinforced the work of Shudy, by demonstrating with the use of a highpull headgear that one can prevent the eruption of the maxillary arch, and thus the mandibular arch may be permitted to use a greater proportion of the growing intermaxillary space, by erupting forwards as well as occlusally.

Biomechanically, tipping of maxillary molars is more severe using cervical headgear than highpul1 headgear. Chaconas, Caputa and Davis 
(1976) demonstrated this by using a three-dimensional anatomic model of a human skult along with photoelastic techniques. The highpull headgear produced the least tipping tendency, being closer to a bodily movement effect.

Lindgren and Langerstrom (1977) noted the maxillary first molars are commonly used as anchorage teeth for the extraoral facebow. They found there will be a distal tipping of the crown if the force is directed below the fulcrum, mesial tipping if the force is directed above the fulcrum, and bodily translation if the force passes through the fulcrum. In addition to the distal translating force, there will also be an intruding force from an anchorage above the occlusal plane such as a highpull headgear.

In order to study the effect of different arrangements of extraoral force, Lindgren et al., used the Dynamic Extraoral Force Analyser (DEFA) developed by Rusch. Rusch constructed this apparatus to reproduce as closely as possible the conditions in the mouth during extraoral force treatment. They used this DEFA and different forces consisting of one, two, and three elastics, in different directions (highpul1, cervical, and straightpul1) to measure the amount of tipping and translation that occurred in the maxillary first molars. They concluded with the highpull headgear distal translation averaged $2.0 \mathrm{~mm}$. Distal tipping occurred in thirteen cases, or about half the total number (with variation of 1-21 degrees), while mesial tipping occurred in about ten cases (2-10 degrees). The $2.0 \mathrm{~mm}$. of distal bodily translation occurred in four cases (with long outer arms bent upwards with two elastics, and short arms bent 
downwards) with all three variations of elastics.

Bowden (1978) stated the clinician, who applies force through an archwire and bracket to a tooth crown employs a more complex system of forces in the form of a couple, creating a suitable ratio between force and moment system in order to produce pure translation. In the same way headgear forces are applied to the molar tubes, tipping of the teeth readily occurs and pure translation is difficult to achieve unless a number of mechanical principles are observed.

Jacobsen (1979) described the inclination of the line of action of the highpulf headgear. The inclination of the line of action is dependent upon: 1. the point of origin of the force, and 2. the point of attachment of the force. The point of origin of a highpull headgear is the upper part of the back of the head. The point of attachment of the force is the hook on the outer bow of the extraoral assembly. In the highpull headgear, the point of origin of the line of action is located above the center of resistance of the tooth, and then the vertical force component to the tooth will be intrusive.

Jacobsen further stated since the ends of the inner arch of facebows are round, and, in turn, are inserted into round tubes, molar teeth can only be tipped buccally or pallatally by means of a headgear. Translatory buccal movements of molars using a highpull headgear could be achieved if square, rectangular, or ovoid arches were slotted into similarly shaped buccal tubes. The rolling of molar crowns buccally and roots palatally due to application of orthodontic forces with a highpull headgear may be prevented by connecting the two molar bands with a palatal 
bar. Soldering a palatal bar to the molars will cause these teeth to translate to the buccal rather than tip or "roll".

Baldini, Haack, and Weinstein (1981) evaluated two basic arch configurations of extraoral appliances in the transverse dimension. 1.a symetric semicircular shape and 2. a conventional arch form with relatively rigid reinforced anterior segment and divergent distal legs.

The lateral forces produced by activation of a symmetrical extraoral appliance were tested with an instrument consisting of a base platform, two force gauges, a frictionless table, and necessary supports.

The bilateral transverse forces and rotating moments produced by two types of labial arches symmetrically loaded as with extraoral traction was investigated. The significant findings were:

1. In a conventionally shaped inner bow arch with reinforced anterior segment, increasing the length of the legs of the archwire has little effect on transverse forces. Increasing the angles of those legs will significantly increase lateral forces on the attaching molars.

2. In a semicircular archwire, a precise fit between arch and tube will increase both the lateral force and moment on the molar.

3. In a more conventional diverging arch, a precise fit between arch and tube will increase the lateral force as it develops a moment tending to rotate the mesial of the molar to the buccal.

4. A buccal offset mesial to the maxillary molar can result in a measurable decrease in lateral force.

Contasti and Logan (1982) reviewed the biomechanical guidelines for 
headgear application. They pointed out there are three main steps needed to design a headgear to deliver the desired force system:

1. Locate the center of resistance of an object to which the force is to be applied. The object is the maxillary first molar. CR is that point of a constrained body through which a single force will cause translation of that body (Burstone, 1962). CR is located approximately at the trifurcation of the maxillary molar in the region of the middle to apical third of the root (Greenspan, 1970; and Worms, 1973).

2. Construct "the moment line of force" (LFO) based on the direction of force. When the line of force (LF) is applied through the CR no tipping will occur (Constati and Logan, 1982).

3. Based on the desired direction and magnitude of the moment, position the outer bow relative to the LFO.

Andrews (1972) determined six keys to normal occlusion. He examined 120 non-orthodontically treated cases. One of his findings was that the maxillary molar has a negative crown inclination, meaning there is lingual crown inclination and buccal root inclination in the vicinity of nine degrees.

A common problem in orthodontics with the use of highpull extraoral traction from a biomechanical standpoint is the movement of the maxillary molar in three planes of space. As shown through earlier research, the design of the conventional highpull headgear creates the problem of tipping or "rolling" effect to the crowns with concomitant root movement lingually (Merrifield and Cross, 1970; Armstrong, 1971; Hickman, 1974; Berman, 1976). This is contrary to Andrews (1972) concept of gnathological 
occlusion, as well as creating an inefficient biomechanical design. This tipping or "rolling" movement can be prevented through the use of the transpalatal bar in conjunction with extraoral parietal traction. However, in order to translate the molar without the use of the transpalatal bar, a biomechanical system must be incorporated into the inner bow of the facebow to allow for the simultaneous transverse movement of crown and root (Jacobsen, 1979).

Angle (1916) introduced this biomechanical system with his tube and pin appliance. Through the use of a rectangular "ribbon" archwire there was not only-better control of force for the crown movement of the teeth, but also it was the first practical mechanism for the proper control of movements of the roots of teeth.

Angle stated: "be it emphasized that on the correct positions of roots of the teeth depends to a very large degree of the permanance of the normal relations of their crowns." His ribbon arch could be bent buccally or lingually, and then engaged into the bracket and the root would move buccally or lingually.

Strang (1925) coined the term "torque". He defined it as the twisting force of a spring wire when turned upon itself. The use and control of torque enables the orthodontist to accomplish more rapidly than ever before certain forms of tooth root movement. Molars which need to be moved buccally, must also have simultaneous movement of the crown and root further explains Strang. A buccal torque force must be combined with the expansion of the wire to accomplish this movement.

Brodie (1927) noted the design of an appliance should conform to 
the laws, first, of physiology, second, mechanics, and third, art, in that order of importance. The laws in physiology in the appliance should be such that the tooth (both crown and root) should be moved gently and continuously in only one direction. The mechanics should apply molar anchorage control in an additional plane of space as Angle's tube and ribbon arch does according to Brodie.

McKenzie (1927) discussed torque as a force which was not available until the ribbon arch mechanism was developed. Torque becomes a "genie" to work wonders for the wary operator who has mastered it, or a "devil" to defeat the efforts of the unwary orthodontist who has not mastered it. He further emphasizes that the importance of root movement in orthodontic treatment cannot be overestimated.

Angle (1929) described torque power as that force power which is to be derived from the tendency of the metal arch, by reason of its elasticity, to untwist after it has been slightly twisted or torqued on itself in the direction of its long axis. Later in the article he stated torque power enlisted for buccal root movements of molars is ample and maybe under positive complete control.

Angle (1929) discussed the accuracy in making the torque bends in the arch and care in seating the arch within the sheaths, tubes, brackets, etc.. He emphasized his preference for round wires, but noted a change must be made later on in treatment to a rectangular edgewise arch when torque power is needed to give labial or lingual root movements.

Brodie (1933) in his article on torque force discussed the possibility when a bracket attachment connects to a tooth on a flat sided arch, 
it is possible the root apex is caused to move, while the wire, an archwire or a facebow wire, becomes the center of rotation, or is possible to accelerate the movement of the root apex along with the crown for bodily movement.

Sved (1937) discussed the difficulty of incorporating third order bends in large gauge wires. The behavior of the archwire, such as that of the inner bow of a facebow inserted in a buccal tube, is goverened by the following conditions:

1. The kind of attachment use.

2. The principle properties of the material.

3. The shape of the wire.

4. The size of the wire.

5. The distance between attachments.

Sved emphasized in regards to the size of the wire, the resistance to bending wires as the third power of the diameter. In other words, if the diameter is doubled, such as a .045 inner bow of a facebow doubled over on itself, then the resistance to bending is increased eight times.

Rauch (1959) defined torque as the force that enables the orthodontist to control the axial inclinations of teeth and to put them in the harmonizing positions that are so desireable for a nice result. Torque is the force that gives the operator control over the movements of roots of teeth. Torque itself is merely the twisting of a wire. Torque force is created when the wire makes an effort to untwist itself when engaged in the brackets of the mechanism. The twisting of the wire, or the torque force placed in the wire is determined by the direction in 
which you want to move the roots. If one wants to move the maxillary molar roots to the buccal, then one twists the wire in a buccal, downward, clockwise direction. When one engages the wire in the maxillary molar tube (sheath), the wire will attempt to unravel and thus place buccal root torque in the maxillary molar.

Jarabak (1960) believed a small amount of "play" between wire and bracket is necessary to allow for the application of physiological forces. Lee (1979) found 200 grams $/ \mathrm{cm}^{2}$ of enface root surface optimum for proper physiologic tooth movement. Enface root surface was defined as the amount of root surface exposed to the direction of tooth movement. Combining Lee's studies with his own, Rickett's (1979) judged $100 \mathrm{grams} / \mathrm{cm}^{3}$ of enface root surface the optimum value. Thus considering the average tooth size of the maxillary first molar, 135 grams are needed to torque the roots properly and safely.

Jarabak (1963) further explained after orthodontically moving the teeth, the roots must be positioned to direct the forces of occlusion along the long axis of the tooth. He went on to say in order to create buccal root movement by torque requires a force and a couple. The force plus couple equals translation. The force in regards to the highpull headgear are the elastics hooked from the facebow to the headcap; the couple would be from the distal end of the inner bow of the facebow inserted into the buccal attachment.

Thurow (1972) stated the word "torque" has been used in describing the effect on a tooth of the force delivered on a twisted (torqued) wire. Often, confused terminologies, torque and torsion are used to describe 
the twist of a wire. In science, torque is the force (stress that causes the twist). Torsion is the actual twisting that results from torque.

Mitchel1 and Kinder (1973) describes torque as the effect on a tooth when a twisted archwire or auxillary delivers a resultant force to the tooth.

Mitchell went on to state there are basically two methods of applying torque forces in the orthodontic appliance. 1. Involves a device of precise fit, such as the rectangular archwire in the bracket slot of the edgewise appliance. 2. Auxilliaries are added to the conventional fixed appliance which can apply a directed force to a tooth or group of teeth.

Shrody (1974) researched buccal segment reaction to anterior lingual root torque. He showed the lateral (buccolingual) displacement was maximal in the molar region with 25 degrees of active anterior torque. This displacement did not exceed one millimeter in either a buccal or lingual direction.

Nickolai (1975) defined optimum orthodontic force as that which produces a maximum desireable biologic response with minimum tissue damage, resulting in rapid tooth movement with little or no clinical discomfort. In Nickolai's study he showed the size of active torque force needed for bodily movement or root movement of a given tooth is two to three times that employed in simple tipping of the same tooth.

Creekmore (1979) discussed torque and states the major criteria in determining the amount of torque necessary per tooth is dependent upon where the tooth started and where one is to move the tooth. Generally, most torque variation is in the anterior region, and when one gets back 
to the molar region, the less variable the adjustments are for torque.

Thurow (1982) further emphasized that an important conisderation in torque action is the use of undersized wires. Wires that fit the slot or tube too precisely should not be used to torque individual teeth. Wires adjusted to torque individual teeth should be sufficiently undersized. This should amount to .001 or .002 inches (.025 or $.05 \mathrm{~mm}$ ) undersized.

Thurow further defined and revised orthodontic torque from his 1972 opinion as the buccolingual root tipping in which movement of the crown is minimized and movement of the root is maximized. This is usually accomplished orthodontically through the application of force by means of a mechanical torsion (twisting) in the archwire.

The state of the art of orthodontics today requires our goals in occlusion be gnathologically oriented with the most efficient biological tooth movement. An instrument has been developed to show the resultant forces of extraoral traction (DEFA). It seems reasonable by testing the reliability of this instrument, a design for a more efficient extraoral appliance can be determined in keeping with our gnathological goals. 


\section{MATERIALS AND METHODS}

This research investigated the capability of the Dynamic Extraoral Force Analyzer (DEFA) to measure linear deflection as a function of force generated by a torquing highpull headgear, and to suggest a design of a highpull extraoral appliance that would deliver a translatory or buccal torquing moment to the maxillary molar teeth.

The wire dimension chosen was the one usually seen on standard facebows (.045 inch round inner bow).* The distal ends of the inner bow were doubled over in order to incorporate torque in the wire (Jacobsen, 1979). The wires were doubled over through manual manipulation with the use of a universal plier (Fig. 7).

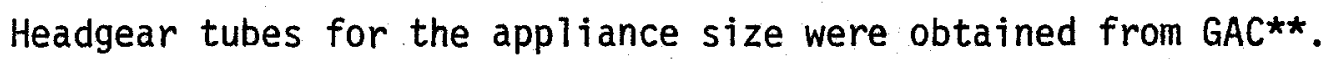
The headgear tubes are for maxillary first molars, which are the most common teeth receiving a headgear.

The testing device was the Dynamic Extraoral Force Analyzer $(D E F A)^{* * *}$. The overall view of the anlayzer is illustrated in figure 8.

* American Orthodontic Corporation, 1714 Cambridge Ave., Sheboygan, Wiscons in 53081 Cat. No. 852-611

** GAC International, Inc. P.0. Box 374, Commack, N.Y. 11725 Cat. No. K9040-MU-22

*** Unitek Corporation, 2724 S. Peck Road,Monrovia, California 91016 Cat. No. HL-255 


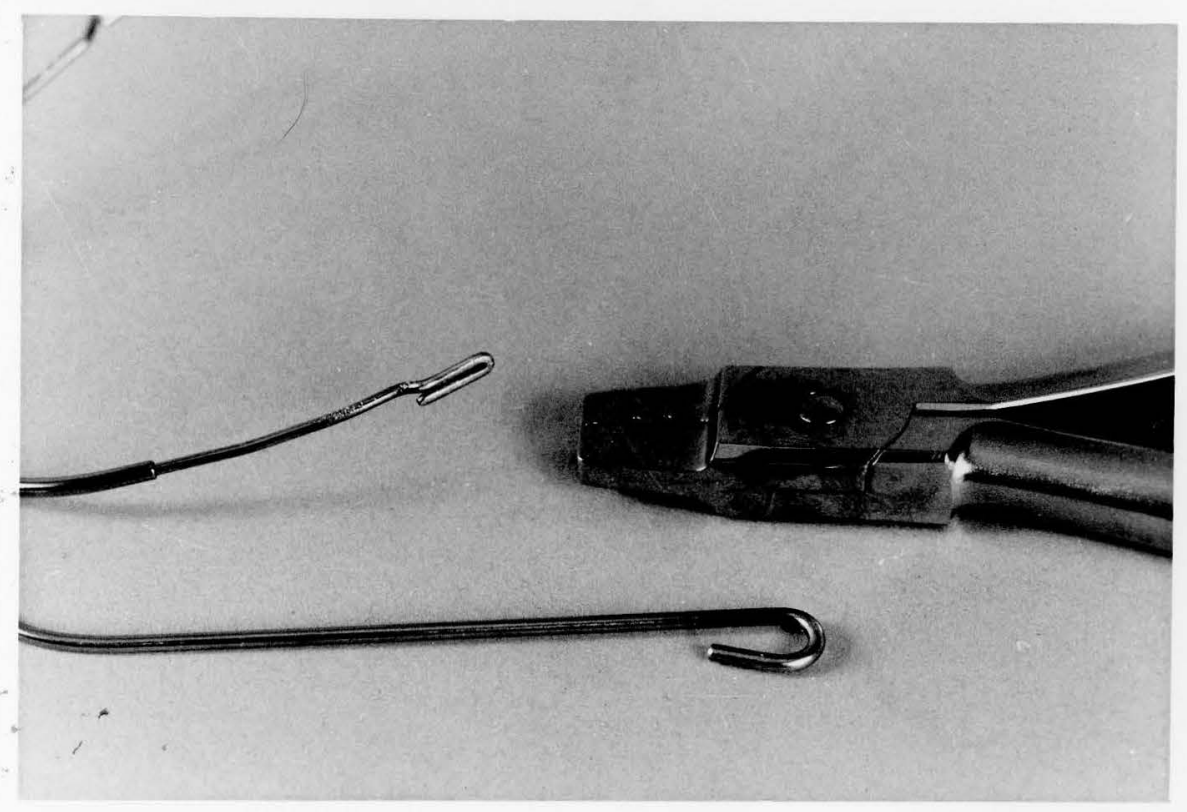

Figure 7. Universal plier and doubled over distal end of inner bow of facebow.

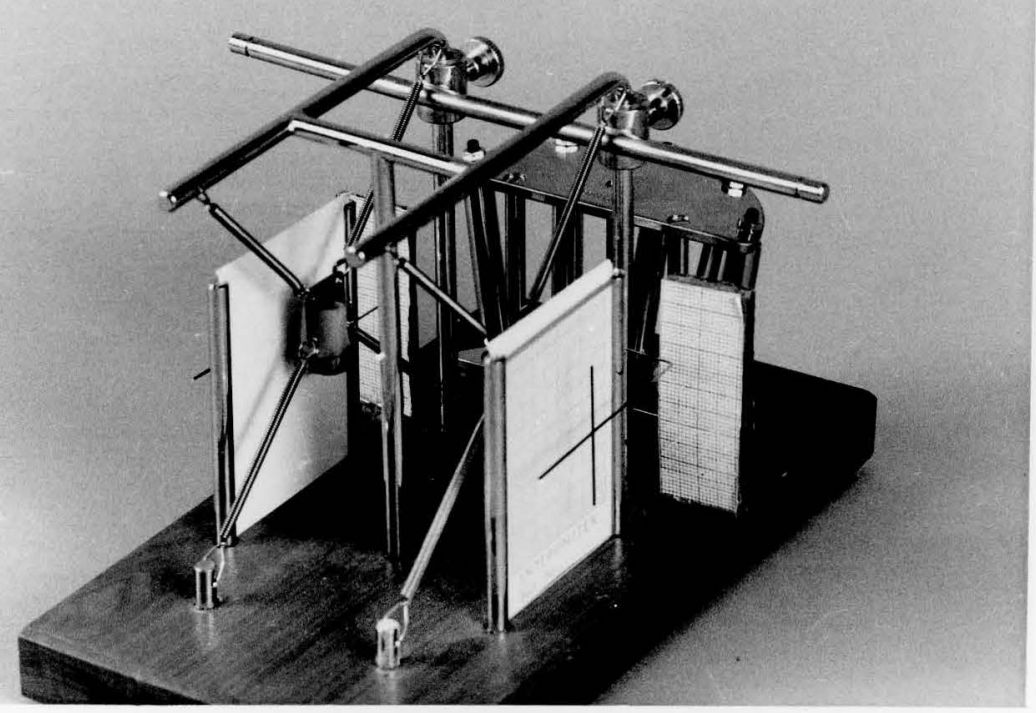

Figure 8. Overall view of the DEFA 
There are two maxillary molars, each molar carries a buccal tube into which the inner large gauge round wire of the facebow is inserted. The molars are suspended by four diagonally arranged springs, holding the two teeth in position under the same tension. The fulcrum (center of resistance) of the suspended molars was marked on the root portion with a metallic point. A cross-like indicator was coupled with and centered over each buccal tube (Fig. 9).

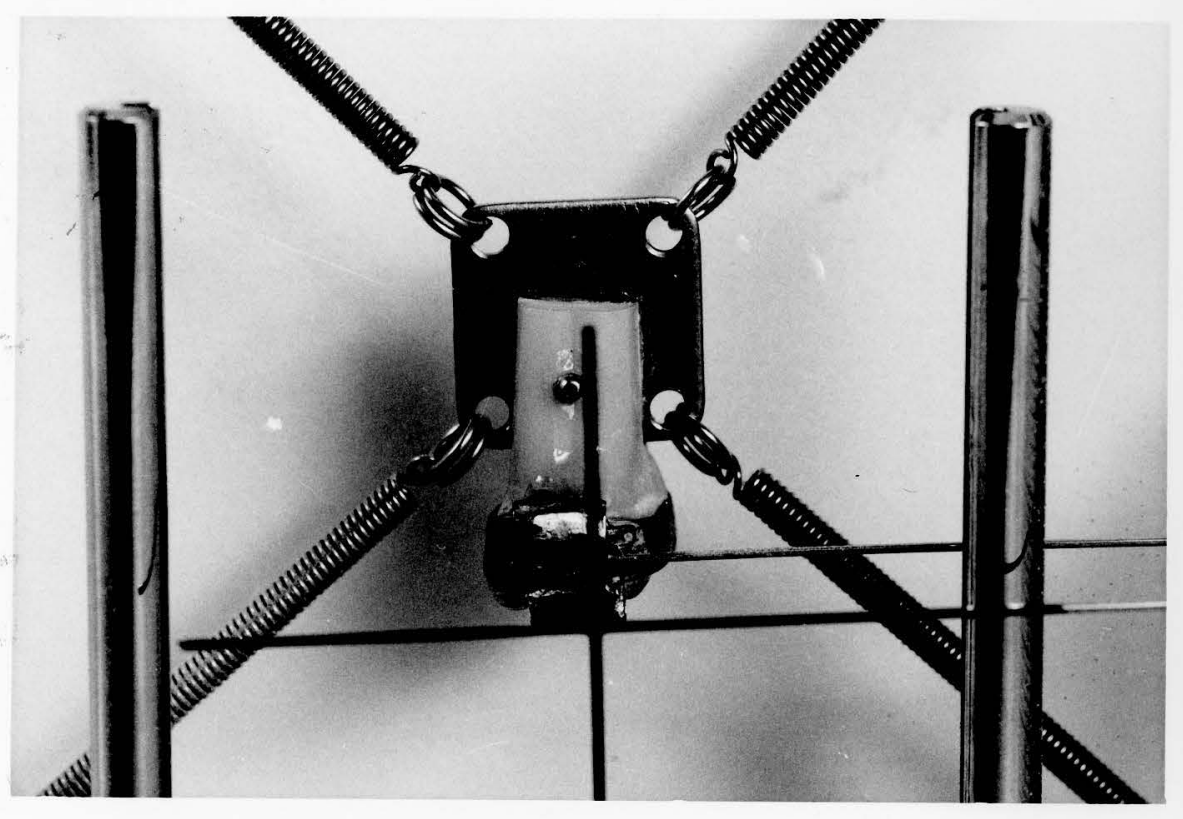

Figure 9. Suspension of maxillary molar by four diagonally arranged springs, cross-like indicator coupled with and centered over each buccal tube, and fulcrum of the suspended molars was marked on the root portion with a metallic point.

A unit grid was interposed between the buccal tube on each side and the respective indicator (Fig. 10).

The vertical arm of the indicator represents the axis of the tooth to which the buccal tube was attached. The horizontal arm lies parallel 


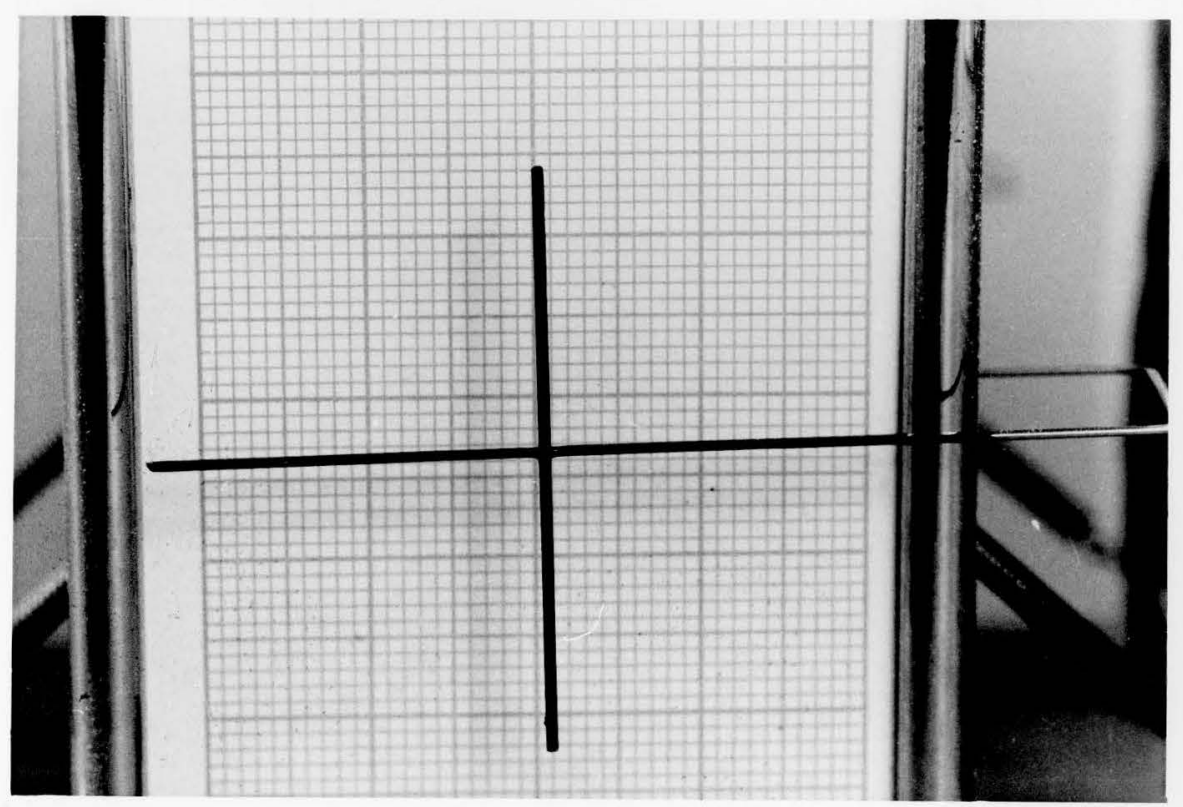

Figure 10. Unit grid interposed between the buccal tube and cross-1ike indicator.

to the occlusal plane. The intersection of the two arms was marked on the unit grid to indicate the position of the buccal tube at rest. A "cervical anchor" is attached to the base of the apparatus to simulate an average topographic relationship between the back of the neck and the maxillary first molars. To simulate occipital traction, a horizontal sliding bar was attached to the vertical posts. Two locking screws permit its adjustment to different positions corresponding to various force direction. Different effects could be demonstrated with the apparatus by changing the plane of the extraoral arch, the lengths of the outer arm or the location of the extraoral anchorage. Different rotational as well as different vertical, horizontal, or lateral force vectors could be induced by altering these variables in any combination. 
Adapted distal to the vertical arm of the cross-like indicator was a unit grid which records the buccal tipping and transverse translation of the maxillary molar (Fig. 11).

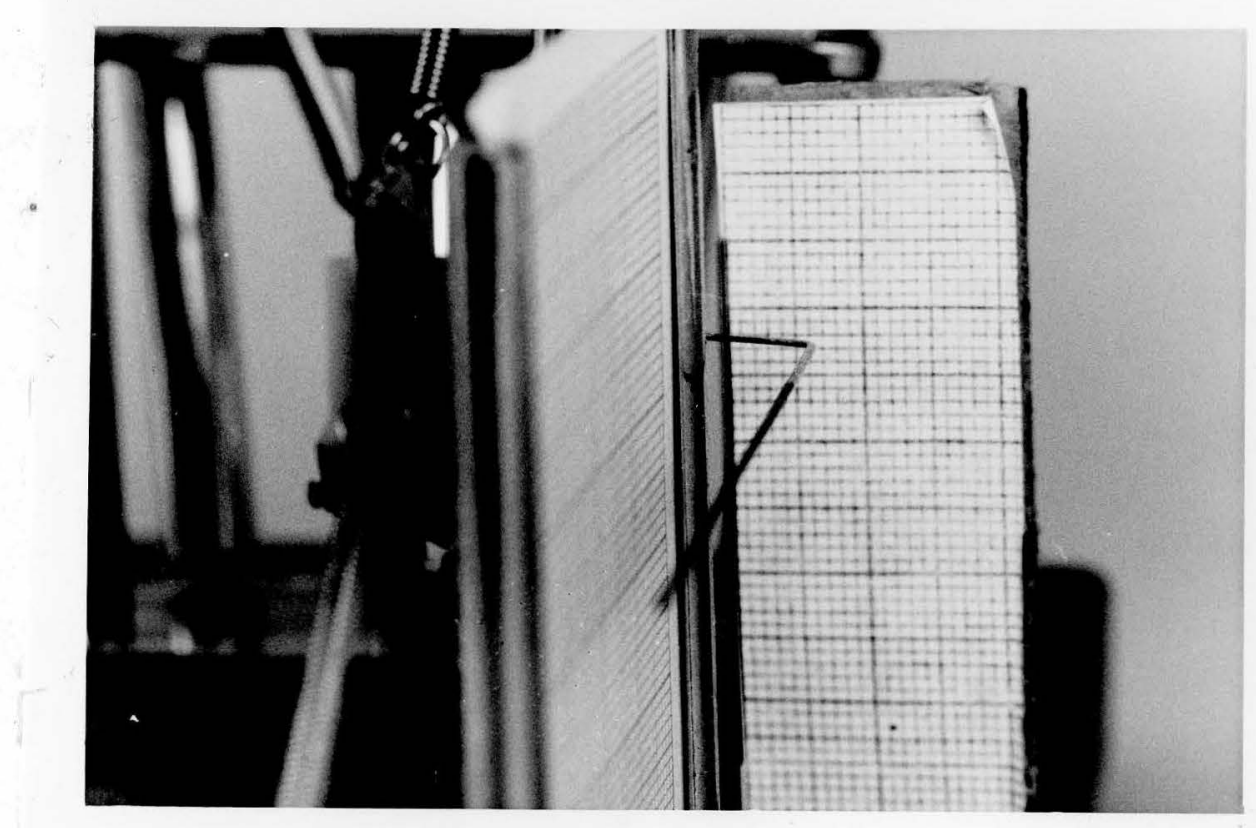

Figure 11. Unit grid adapted distal to the vertical arm of the cross-like indicator.

Initially, ten standard facebows with a cervical direction of pull, and ten standard facebows with a highpull (parietal) direction of pull were tested to determine the reliability of the DEFA. The cervical facebows were placed into headgear tubes of .045 inch diameter. The facebows consisted of a .045 inch inner bow with a standard medium outer bow. The inner bow was in the same plane as the outer bow. One six ounce elastic $\left(\frac{1}{4}\right.$ in. $) *$ was connected from each outer bow to the horizontal sliding bar on the vertical post 33 millimeters above the wooden base of the DEFA.

* Unitek Corporation, 2724 S. Peck Road, Monrovia, California 91016 Cat. No. 404-636 
This was the ideal height needed to simulate the direction of pull for a cervical headgear (Rusch, 1982). At this point the units of distal tipping of the maxillary molar were recorded. This measurement was recorded by a cross-like indicator coupled with and centered over each buccal tube on the maxillary molar. A unit grid was interposed between the buccal tube on each side and the cross-like indicator. The cross-like indicator recorded on the unit grid the number of units of distal tipping. This was recorded by visual inspection. Following these measurements, the same ten cervical facebows were tested in a blind study to determine reproduceability of the instrument. The apparatus, materials used, and means of measurement were the same as those used for the cervical facebows.

The same procedure was used to determine reproduceability of the instrument with highpull (parietal) headgear. One six ounce elastic $\left(\frac{1}{4}\right.$ in.) was connected from each outer bow to the horizontal sliding bar on the vertical post 83 millimeters above the wooden base of DEFA. This was the ideal height needed to simulate the direction of pull for a highpull headgear (Rusch, 1982). At this point the units of distal tipping of the maxillary molar were recorded. These measurements were recorded in exactly the same manner as was used for the cervical facebows. Following these measurements, the same ten highpull facebows were tested in a blind study. The apparatus, materials used, and means of measurement were the same as those used for the ten highpull facebows.

Having determined reproduceability of the DEFA, an experimental protocol was developed to determine the extent of various measurements 
of the maxillary molar.

Five (coded A-E) .045 inch doubled over distal end inner bows were tested to determine which force was needed for translation of the maxillary molar to occur.

Initially, the facebows with a highpull (parietal) direction of pul1, and zero degrees of torque in the doubled over distal end of the inner bow were used as controls. The facebows were placed into headgear tubes of slightly greater than .090 inch diameter for the .045 doubled over inner bow. The outer bows of the facebows were of standard medium length and were bent at an angle that would pass through the center of resistance of the maxillary first molar to produce the least amount of anterior-posterior tipping, and greatest amount of anterior-posterior transiation (Greenspan, 1970; Armstrong, 1971; Jacobsen, 1979). One two ounce, * four ounce, ${ }^{*}$ and six ounce* elastic at separate times were connected from each outer bow to the horizontal sliding bar on the vertical posts. The distance that each elastic stretched on the right and left side from the outer bow of the facebow to the horizontal sliding bar was recorded to the nearest .001 inch with the use of a Helios Dial Gauge Caliper (Fig. 12). Three readings on the right side, along with three readings on the left side and their respective average readings were recorded. With each size elastic connected from the outer bow to the horizontal sliding bar, five separate readings and their respective

* Unitek Corporation, 2724 S. Peck Road, Monrovia, California 91016 Cat. No. 404-146, 404-536, 404-636 


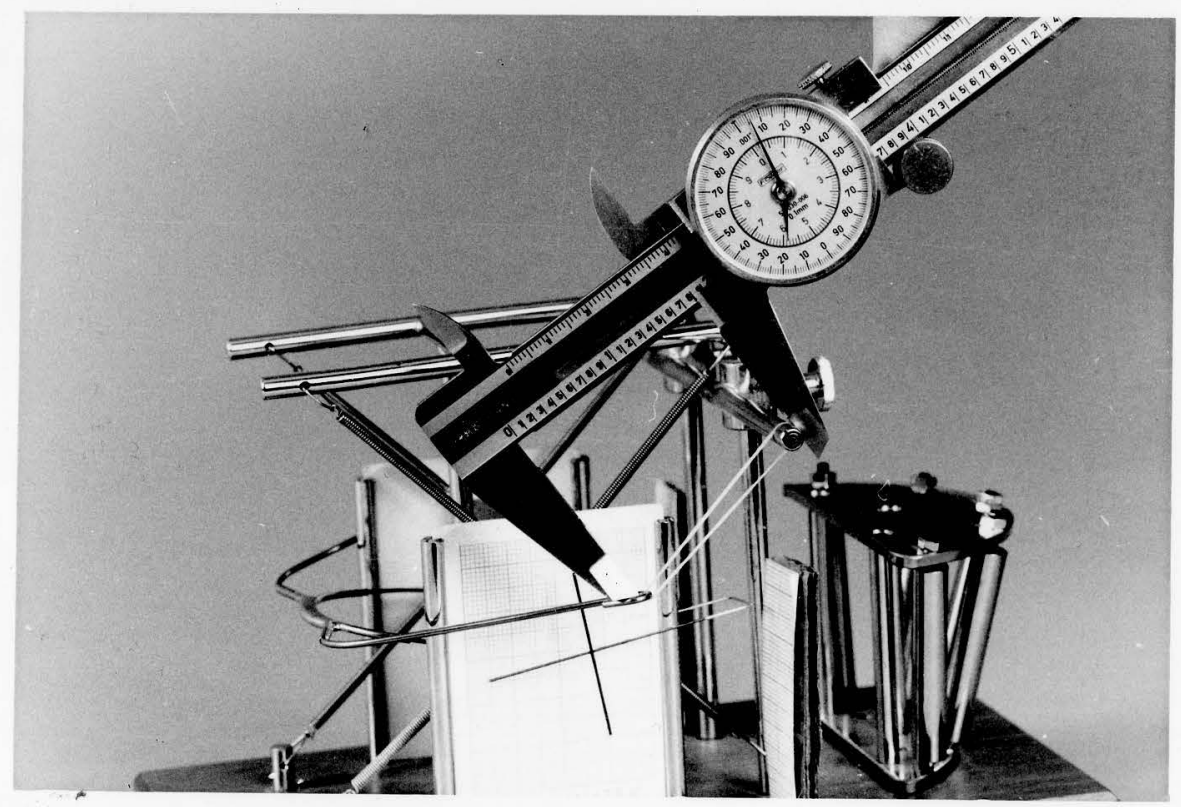

Figure 12. Dial Gauge Caliper measuring stretch of elastic from outer bow to horizontal sliding bar.

average of the units of distal tipping, anterior-posterior translation, transverse translation, and buccal crown tipping of the right and left maxillary molar were recorded. The cross-like indicator recorded on a unit grid the number of units of distal tipping and anterior-posterior translation. The length of the vertical arm from its point of intersection with the horizontal arm of the indicator to its end was $16.5 \mathrm{milli-}$ meters. It was at the end of the vertical arm where the number of units of buccal crown tipping and transverse translation were recorded on the unit grid adapted distal to the vertical arm. These measurements were recorded by visual inspection. The force generated by three elastics were measured and recorded by an Instron Model 1130 Universal Testing Machine*

* Instron Corporation, Canton, Mass. 
with a 10 pound load cell at one pound full scale. The force measurements were recorded at 60 second intervals following the initial stretch of the elastic. Each elastic was stretched its respective average right and left lengths on the Instron Universal Testing Machine as determined earlier by the Dial Gauge Caliper.

Following the testing of the five control facebows; five experimental facebows with a highpull (parietal) direction of pull and nine degrees of buccal root torque incorporated in the doubled over distal ends of the inner bow were tested. This amount was found to be the ideal gnathological axial inclination of maxillary first molars (Andrews, 1972). The amount of buccal root torque was determined using an acrylic template and a grid marked with a nine degree angle. The doubled over distal end of the inner bow was placed perpendicular to a flat surface. An acrylic template with a slot large enough to fit securely over the doubled over distal end was made. A grid with a nine degree angle was placed behind the acrylic template and the doubled over distal end. The doubled over distal end was manually bent, and the acrylic template was moved until the doubled over distal end, the acrylic template and the nine degree angle on the grid were in the same plane.

The facebows were placed into headgear tubes of slightly greater than .090 inch diameter, for the .045 inch doubled over inner bow. Measurements of the torqued facebows were performed in a fashion identical to that for the untorqued controls. The three elastics $(2,4,6$ ounce) were applied to the facebow sequentially until there was very little if any buccal crown tipping, along with transverse translation of the maxillary first molar. 


\section{CHAPTER IV}

\section{RESULTS}

The initial results are summarized in tables I-IV. Tables I-II show the actual units of distal tipping that occurred in maxillary first molars with ten facebows having a cervical and highpull direction of pull. Two separate readings were taken for each numbered facebow.

A statistical analysis of this data is presented in table III which shows that no difference exists between readings and therefore reproduceability of the- DEFA had been demonstrated.

Table IV shows that a significant difference exists between cervical and highpull direction with regard to distal tipping.

Following the initial results, appendix tables $A-1$ through $A-14$ show the raw data of the research.

Appendix tables A-1 through A-6 show data with respect to the control facebows with zero torque, and doubled over distal end facebows with nine degrees of torque, and their respective two, four, and six ounce elastic force. These tables display the distance that each elastic stretched on the outer bow to the horizontal sliding bar on the vertical posts of the DEFA.

Appendix tables A-7 through A-12 show the control facebows with zero degrees of torque, the doubled over distal end facebows with nine degrees of torque, and their respective two, four, and six ounce elastic 
force. These tables display the units of distal crown tipping, anteriorposterior translation, transverse translation, and buccal crown tipping of the right and left maxillary molar.

Appendix tables $A-13$ and A-14 show t-values of non-torqued and torqued facebows for various magnitudes of force for buccal and distal crown tipping, anterior-posterior and transverse translation of the maxillary right and left molar.

Table $V$ displays the average distance and force readings the two, four, and six ounce elastics were stretched from the outer bows of torqued and non-torqued facebows.

Table VI shows the means and standard deviations for buccal crown tipping and transverse translation of the maxillary right and left molar of torqued and non-torqued facebows for various magnitudes of force.

A statistical analysis of this data is presented in tables VII, VIII, IX and $X$. In summary three sets of t-tests were calculated. They were as follows:

1. Student t-values of non-torqued facebows for various magnitudes of force for buccal crown tipping and transverse translation of the maxillary right and left molar (Table VII).

2. Student $t$-values of torqued facebows for various magnitudes of force for buccal crown tipping and transverse translation of the maxillary right and left molar (Table VIII).

3. Student t-values of torqued vs. non-torqued facebows for various magnitudes of force for buccal crown tipping and transverse translation of the maxillary right and left molar (Tables IX and X). 
Table VII displays a statistical significance for buccal crown tipping of the maxillary right and left molar; however there is no statistical significance at any force level for transverse translation of the right or left molar.

Table VIII shows a statistical significance at the two ounce vs. four ounce, and the two ounce vs. six ounce level for all tooth movements; however, there is no significance at the four ounce vs. six ounce level for any tooth moyement.

Tables IX and $X$ show no statistical significance at any force vs. two ounce torque for transverse translation; however, there is statistical significance at any force vs. four ounce torque or six ounce torque for transverse translation of the maxillary right and left molar. 
Table I

Distal Tipping of Maxillary First Molars With Cervical Traction Facebows

Facebow

1

2

3

4

5

6

7

8

9

10
Facebow Reading 1 (units)

5.0

4.5

4.0

4.5

4.5

4.0

5.0

4.5

5.0

5.0
Facebow Reading 2 (units)

4.5

4.0

4.0

4.0

4.5

4.0

5.0

5.0

5.0

5.0 
Table II

Distal Tipping of Maxillary First Molars With Highpull Traction Facebows

\begin{tabular}{ccc} 
Facebow & Facebow Reading I (units) & Facebow Reading 2 (units) \\
\cline { 2 - 3 } 1 & 2.0 & 2.0 \\
2 & 1.5 & 2.0 \\
3 & 1.5 & 2.0 \\
4 & 2.0 & 2.0 \\
5 & 2.5 & 2.0 \\
6 & 2.0 & 1.5 \\
7 & 2.0 & 1.5 \\
8 & 1.5 & 1.5 \\
9 & 1.5 & 2.0 \\
10 & 2.0 & 1.5
\end{tabular}


Means, Standard Deviations, and 95\% Confidence Measurements of Cervical and

Highpull Traction Facebow Readings

Cervical Traction Comparison between first and second

Facebow reading $n \quad \bar{X}$ (units) S.D. (units) $95 \%$ Confidence (units) measurements

1

$10 \quad 4.60$

.39

.47

$3.82-5.38$

$3.56-5.44$

Highpull Traction

Comparison between first and second

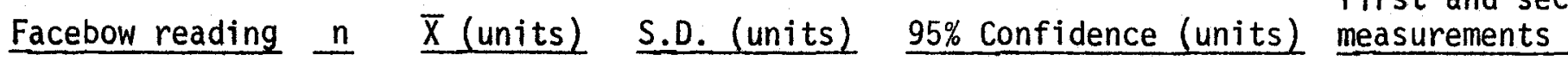

1

$10 \quad 1.85$

.34

.26

$1.17-2.53$

$1.28-2.32$

$\frac{t}{23}$ 
Table IV

T-Comparison of Cervical Traction Readings vs. Highpull Traction Readings

Facebow Reading

1

2 (df)

9

9 $t$

14.50

10.87

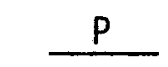

$<.0001$

$<.0001$ 
Table V

Average Distance and Specific Force Readings That Elastics Were Stretched From Outer Bows of Torqued and Non-torqued Facebows to Vertical Post of the DEFA.

\begin{tabular}{|c|c|c|c|}
\hline Torque (degrees) & $\begin{array}{l}\text { Force (ounce } \\
\text { per side) }\end{array}$ & Specific force (grams) & Average distance (inches) \\
\hline 0 & 2 & $\begin{array}{l}\text { range }=79.45-99.88 \\
X=93.98 \\
\text { S.D. }=6.54\end{array}$ & 1.968 \\
\hline 0 & 4 & $\begin{array}{l}\text { range }=170.25-238.35 \\
\bar{X}=202.03 \\
\text { S.D. }=21.08\end{array}$ & 1.821 \\
\hline 0 & 6 & $\begin{array}{l}\text { range }=324.61-376.82 \\
\bar{X}=345.04 \\
\text { S.D. }=19.32\end{array}$ & 1.741 \\
\hline 9 & 2 & $\begin{array}{l}\text { range }=81.72-131.66 \\
\bar{X}=101.92 \\
\text { S.D. }=15.67\end{array}$ & 1.972 \\
\hline 9 & 4 & $\begin{array}{l}\text { range }=177.06-229.27 \\
X=199.76 \\
\text { S.D. }=20.25\end{array}$ & 1.843 \\
\hline 9 & 6 & $\begin{array}{l}\text { range }=315.53-389.53 \\
X=347.08 \\
\text { S.D. }=26.69\end{array}$ & 1.746 \\
\hline
\end{tabular}


Mean and Standard Deviations for Buccal Tipping ahd Transverse Translation of Maxillary Right and Left Molar of Torqued and Non-torqued Facebows for Various Magnitudes of Force.

\begin{tabular}{|c|c|c|c|c|c|}
\hline $\begin{array}{l}\text { Torque } \\
\text { (degrees) }\end{array}$ & $\begin{array}{l}\text { Force } \\
\text { (ounce } \\
\text { per side) }\end{array}$ & $\begin{array}{l}\text { Buccal Tipping } \\
\text { Max. rt. } \\
\text { molar }\end{array}$ & $\begin{array}{l}\text { Transverse } \\
\text { Translation } \\
\text { Max. rt. molar }\end{array}$ & $\begin{array}{l}\text { Buccal Tipping } \\
\text { Max. 1t. } \\
\text { molar }\end{array}$ & $\begin{array}{l}\text { Transverse } \\
\text { Translation } \\
\text { Max. 1t. molar }\end{array}$ \\
\hline 0 & 2 & $\begin{array}{l}N=25 \\
\bar{X}=.72 \\
\text { S.D. }=.22\end{array}$ & $\begin{array}{l}\frac{N}{X}=25 \\
X=0.0 \\
\text { S.D. }=0.0\end{array}$ & $\begin{array}{l}N=25 \\
\bar{X}=.72 \\
\text { S.D. }=.16\end{array}$ & $\begin{array}{l}\frac{N}{X}=25 \\
X=0.0 \\
\text { S.D. }=0.0\end{array}$ \\
\hline 0 & 4 & $\begin{array}{l}N=25 \\
\bar{X}=1.0 \\
\text { S.D. }=.07\end{array}$ & $\begin{array}{l}\frac{N}{X}=25 \\
\text { S.D. }=0.0 \\
\text { S.0 }\end{array}$ & $\begin{array}{l}\frac{N}{X}=25 \\
=.98 \\
\text { S.D. }=.08\end{array}$ & $\begin{array}{l}\frac{N}{X}=25 \\
X=0.0 \\
\text { S.D. }=0.0\end{array}$ \\
\hline 0 & 6 & $\begin{array}{l}N=25 \\
\bar{X}=1.54 \\
\text { S.D. }=.05\end{array}$ & $\begin{array}{l}\frac{N}{X}=25 \\
X=0.0 \\
\text { S.D. }=0.0\end{array}$ & $\begin{array}{l}N=25 \\
\bar{X}=1.54 \\
\text { S.D. }=.05\end{array}$ & $\begin{array}{l}\frac{N}{X}=25 \\
X . D .=0.0 \\
\text { S.D. } 0.0\end{array}$ \\
\hline 9 & 2 & $\begin{array}{l}\frac{N}{X}=25 \\
\bar{X}=.56 \\
\text { S.D. }=.06\end{array}$ & $\begin{array}{l}N=25 \\
\bar{X}=0.0 \\
\text { S.D. }=0.0\end{array}$ & $\begin{array}{l}N=25 \\
\bar{X}=.56 \\
\text { S.D. }=.05\end{array}$ & $\begin{array}{l}N=25 \\
\bar{X}=0.0 \\
\text { S.D. }=0.0\end{array}$ \\
\hline 9 & 4 & $\begin{array}{l}N=25 \\
\frac{N}{X}=0.0 \\
\text { S.D. }=0.0\end{array}$ & $\begin{array}{l}N=25 \\
X=.94 \\
\text { S.D. }=.05\end{array}$ & $\begin{array}{l}N=25 \\
\bar{X}=0.0 \\
\text { S.D. }=0.0\end{array}$ & $\begin{array}{l}N=25 \\
\bar{X}=.94 \\
\text { S.D. }=.05\end{array}$ \\
\hline 9 & 6 & $\begin{array}{l}N=25 \\
\bar{X}=0.0 \\
\text { S.D. }=0.0\end{array}$ & $\begin{array}{l}\frac{N}{X}=25 \\
X=.94 \\
\text { S.D. }-.05\end{array}$ & $\begin{array}{l}\frac{N}{X}=25 \\
X=0.0 \\
\text { S.D. }=0.0\end{array}$ & $\begin{array}{l}N=25 \\
\bar{X}=.96 \\
\text { S.D. }=.05\end{array}$ \\
\hline
\end{tabular}


T-Comparisons of Non-torqued Facebows for Various Magnitudes of Force for Buccal Tipping and Transverse Translation of Maxillary Right and Left Molar

\begin{tabular}{|c|c|c|c|c|}
\hline Iooth Movement & $d f$ & $\begin{array}{l}\text { two ounce vs. } \\
\text { four ounce. }\end{array}$ & $\begin{array}{l}\text { two ounce vs. } \\
\text { six ounce }\end{array}$ & $\begin{array}{l}\text { four ounce vs } \\
\text { six ounce }\end{array}$ \\
\hline $\begin{array}{l}\text { Buccal Tipping } \\
\text { Max. rt. molar }\end{array}$ & 9 & $2.7 *$ & $8.1 *$ & $14.0 * *$ \\
\hline $\begin{array}{l}\text { Transverse Translation } \\
\text { Max. rt. molar }\end{array}$ & 9 & 0.0 & 0.0 & 0.0 \\
\hline $\begin{array}{l}\text { Buccal Tipping } \\
\text { Max. 1t. molar }\end{array}$ & 9 & $3.2^{*}$ & $10.9 * *$ & $13.3^{* *}$ \\
\hline $\begin{array}{l}\text { Transverse Translation } \\
\text { Max. 1t. molar }\end{array}$ & 9 & 0.0 & 0.0 & 0.0 \\
\hline
\end{tabular}


T-Comparisons of Torqued Facebows for Various Magnitudes of Force for Buccal Tipping and Transverse Translation of Maxillary Right and Left Molar.

\begin{tabular}{|c|c|c|c|c|}
\hline Tooth Movement & $d f$ & $\begin{array}{l}\text { two ounce vs. } \\
\text { four ounce }\end{array}$ & $\begin{array}{l}\text { two ounce vs. } \\
\text { six ounce }\end{array}$ & $\begin{array}{l}\text { four ounce vs } \\
\text { six ounce }\end{array}$ \\
\hline $\begin{array}{l}\text { Buccal Tipping } \\
\text { Max. rt. molar }\end{array}$ & 9 & $20.9 \star \star$ & $20.9 * \star$ & 0.0 \\
\hline $\begin{array}{l}\text { Transverse Translation } \\
\text { Max. rt. molar }\end{array}$ & 9 & $42.0 * *$ & $42.0 * *$ & 0.0 \\
\hline $\begin{array}{l}\text { Buccal Tipping } \\
\text { Max. it. molar }\end{array}$ & 9 & $25.0 * \star$ & $25.0^{\star \star}$ & 0.0 \\
\hline $\begin{array}{l}\text { Transverse Translation } \\
\text { Max. it. molar }\end{array}$ & 9 & $42.0 * \star$ & $42.8^{* *}$ & 0.6 \\
\hline
\end{tabular}


Table IX

T-Comparisons of Torqued vs. Non-torqued Facebows for Various Magnitudes of Force for Buccal Tipping and Transverse Translation of Maxillary Right and Left Molar

\begin{tabular}{|c|c|c|c|c|c|c|c|}
\hline Tooth Movement & $d f$ & $\begin{array}{l}\text { two ounce } \\
\text { no torque } \\
\text { vs. two } \\
\text { ounce torque }\end{array}$ & $\begin{array}{l}\text { two ounce } \\
\text { no torque } \\
\text { vs. four } \\
\text { ounce torque } \\
\end{array}$ & $\begin{array}{l}\text { two ounce } \\
\text { no torque } \\
\text { vs. six } \\
\text { ounce torque } \\
\end{array}$ & $\begin{array}{l}\text { four ounce } \\
\text { no torque } \\
\text { vs. two } \\
\text { ounce torque } \\
\end{array}$ & $\begin{array}{l}\text { four ounce } \\
\text { no torque } \\
\text { vs. four } \\
\text { ounce torque }\end{array}$ & $\begin{array}{l}\text { four ounc } \\
\text { no torque } \\
\text { vs. six } \\
\text { ounce tor }\end{array}$ \\
\hline $\begin{array}{l}\text { Buccal Tipping } \\
\text { Max. rt. molar }\end{array}$ & 9 & 1.6 & $7.3 * *$ & $7.3 * \star$ & $10.7^{\star \star}$ & $31.9 * \star$ & $31.9 * *$ \\
\hline $\begin{array}{l}\text { Transverse } \\
\text { Translation } \\
\text { Max. rt. molar }\end{array}$ & 9 & 0.0 & $42.0 * *$ & $42.0 * \star$ & 0.0 & $42.0 * \star$ & $42.0 * \star$ \\
\hline $\begin{array}{l}\text { Buccal Tipping } \\
\text { Max. Lt. Molar }\end{array}$ & 9 & 2.1 & $10.1^{* *}$ & $10.1^{* \star}$ & $9.9 * *$ & 27.4 ** & $27.4 * *$ \\
\hline $\begin{array}{l}\text { Transverse } \\
\text { Translation } \\
\text { Max. It. molar }\end{array}$ & 9 & 0.0 & $42.0 * \star$ & $42.8^{* *}$ & 0.0 & $42.0 * \star$ & $42.8^{* *}$ \\
\hline
\end{tabular}


Table $X$

T-Comparisons of Torqued vs. Non-torqued systems for various Magnitudes of Force for Buccal Tipping and Transverse Translation of Maxill lary Right and Left Molar. six ounce no torque six ounce no torque six ounce no torque vs. vs. vs.

Tooth Movement df two ounce torque four ounce torque six ounce torque

\begin{tabular}{|c|c|c|c|c|}
\hline $\begin{array}{l}\text { Buccal Tipping } \\
\text { Max. rt. molar }\end{array}$ & 9 & $28.1^{\star *}$ & $68.7^{* *}$ & $68.7 * *$ \\
\hline $\begin{array}{l}\text { Transverse } \\
\text { Translation } \\
\text { Max. rt. molar }\end{array}$ & 9 & 0.0 & $42.0 * \star$ & $42.0 * *$ \\
\hline $\begin{array}{l}\text { Buccal Tipping } \\
\text { Max. it. molar }\end{array}$ & 9 & $31.0 * *$ & $68.7 * \star$ & $68.7 * \star$ \\
\hline $\begin{array}{l}\text { Transverse } \\
\text { Translation } \\
\text { Max. 1t. molar }\end{array}$ & 9 & 0.0 & $42.0 * \star$ & $42.8 * \star$ \\
\hline
\end{tabular}

$\star \star-P<.01$ 
CHAPTER V

\section{DISCUSSION}

The large amount of distal tipping seen in the standard .045 inch facebows with cervical traction was due to the fact the outer bow and inner bow are in the same plane, with the outer bow positioned below the center of resistance of the maxillary first molar. Positioning the outer bow below the center or resistance with a moderate force from the cervical direction created a clockwise moment to occur with a distal tipping of the crown.

The distal tipping component of the standard highpull (parietal) facebows was less severe than cervical facebows due to the point of origin of the force. The point of attachment of the force on both the cervical and the highpull facebow was the hook on the outer bow. However, the point of origin of the line of action differs. With the cervical facebow, the point of origin of the line of action was the back of the neck, which was located below the center of resistance of the tooth. Therefore a greater horizontal component was delivered to the tooth. In the highpull facebow, the point of origin was the parietal area of the head, which was located above the center of resistance of the maxillary molar. Thus there was a greater vertical force component and less horizontal distal tipping component.

A paired $t$-test between the two cervical traction facebow readings, 
and a paired t-test between the two highpull traction facebow readings indicated there was no difference between the two cervical traction facebow readings, and there was no difference between the two highpull traction facebow readings. Therefore, the DEFA testing facebows with either a cervical or highpull direction of pull has the capability of reproduceable values and was accurate in differentiating directions of pull and their respective values of facebow readings.

Table $V$ indicates the average distance of elastic stretch decreased for torqued and non-torqued facebows as the size of the elastic increased. As the force increased, the outer bow was pulled back moving closer to the vertical post, thus the distance the elastic was stretched decreased from the outer bow to the vertical post.

Table VI indicates as the size of the elastics increased in the nontorqued facebows, the amount of buccal tipping of the maxillary right and left molar increased. This is in agreement with Merrifield and Cross (1970), Armstrong (1971), Hickman (1974) and Berman (1976) who have al1 shown from a biomechanical standpoint, the round wire of a highpull headgear creates the problem of a tipping or "rolling" effect of the maxillary molar crowns to the buccal. As the force of the elastic increased on a highpull headgear, the magnitude of buccal crown tipping of maxillary molars increased. With non-torqued facebows there existed no transverse translation of either the maxillary right or left molar. No transverse translatory movements of maxillary molars with a highpull headgear occurred due to the fact the ends of the inner arch of facebows were round, and, in turn, were inserted into round tubes. Molar teeth could only be 
tipped and not translated. Translatory buccal movements of molars using a highpull headgear could be achieved if square, rectangular, ovoid or doubled over round arches with torque incorporated in them were slotted into similarly shaped buccal tubes (Jacobsen, 1979). The torqued doubled over round distal ends with four and six ounces of force did produce transverse translation of the maxillary right and left molar. The very similar readings of buccal tipping and transverse translation of the maxillary right and left molar between the facebows with similar force and torque would also indicate the manufacturers reliability of the solder joints uniting the inner and outer bow of the facebow.

Buccal tipping did occur, however, transverse translation did not occur in a non-torqued facebow, and was verified statistically for buccal tipping, while no statistical significance for transverse translation of the molar was found.

Four and six ounce elastics in a torqued facebow did not produce buccal tipping movement in the maxillary right or left molar. The only movement seen was transverse translation of the molars. However, there was no greater transverse translation with six ounce elastics compared to four ounce elastics. The reason for this was the rigidity of the inner bow inserted into the buccal tube. Most likely if the elastic force continued to increase, the amount of transverse translation would increase in smaller increments. The nine degrees of torque, along with a moderate four or six ounce (200-347 grams) elastic allows the molar to translate with no buccal tipping. Lee (1979) showed that 135-205 grams was the force needed for transverse translation of a maxillary molar. 
As the elastic force continued to increase from no torque values of two, four, and six ounces vs. torque values of two, four, and six ounces the statistical difference of buccal tipping continued to increase with only a couple exceptions at six ounce no torque vs. two ounce torque for the maxillary right molar, and four ounce no torque vs. two ounce torque for the maxillary left molar. However, the respective decrease in tvalues of 3.8 ( 31.9 to 28.1$)$ and 0.2 (10.1 to 9.9) were very small and did not affect the statistical significance. The two, four, and six ounce no torque vs. the four, and six ounce torqued systems were statistically significant for transverse translation of the maxillary right and left molar. This showed with four or six ounce (200-347 grams) elastics on a torqued facebow transverse translation did occur. However, with two, four, or six ounce (94-345 grams) elastics on a non-torqued facebow no transverse translation occurred. Therefore, the data showed a force in a torqued facebow of four to six ounces (200-347 grams) was needed to bring about transverse translation of the maxillary right or left molar with a highpull torquing headgear design of .045 inch round inner bow with doubled over distal ends, and nine degrees of torque incorporated in the distal ends.

Transverse translation did occur in a torqued facebow as the data indicated. However, the amount of transverse translation occurring was minimal with a mean value of .95 units. The DEFA was a crude instrument with crude linear measurements and limited in its use. Perhaps a more scientific instrument with a greater scope of measurements and expanded usage would have improved the quantity of units of transverse translation. 
An increase in magnitude of force consisting of eight, ten, or twelve ounces might increase the units of transverse translation; however, the DEFA was limited to the amount of force applied to it. Another type of facebow design consisting of a rectangular, or ovoid distal end rather than a doubled over round distal end may have increased the units of transverse translation. A continuation of this research may consist of varying the amount of torque or lateral expansion of the inner bow while maintaining a constant force. As laboratory research, the minimal amount of transverse translation occurring may not be enough to be significant clinically. - The human tooth along with the surrounding bone, soft tissue, and periodontal ligament may not be translated as was shown in the laboratory. This is questionable and further research is needed in this area concerning clinical significance. 


\section{SUMMARY}

The purpose of this study was to determine the capability of the Dynamic Extraoral Force Analyzer (DEFA)* to measure linear deflection as a function of force created by a headgear, and to suggest a design of a practical highpull extraoral appliance that would deliver a translatory or buccal torquing moment to the maxillary molar to retard the buccal tipping or "rolling" effect created by the highpull headgear.

Fifteen facebows were examined. Ten standard facebows with a cervical direction of pull, and the same ten standard facebows with a highpull (parietal) direction of pull were tested to determine the reliability of the DEFA. The ten facebows consisted of a .045 inch inner bow with a standard medium outer bow. The inner bow was in the same plane as the outer bow, and were placed into headgear tubes of .045 inch diameter. One six ounce elastic was connected from each outer bow to the horizontal sliding bar on the vertical post of the DEFA. The units of distal tipping of the maxillary molar was recorded by a cross-like indicator on a unit grid. Statistical analysis was made to determine the reliability of the DEFA, the reproduceability of its measurements, and the accuracy in differentiating different directions of pull.

* Unitek Corporation, 2724 S. Peck Road, Monrovia, California 91016 Cat. No. HL-255 
Following the testing of the ten standard facebows with a cervical and highpull (parietal) direction of pull; five standard facebows with doubled over distal ends and zero degrees of torque were tested as controls. The same five standard facebows as above with the exception of nine degrees of torque, instead of zero degrees, were tested as the experimental facebows. The outer bows were not in the same plane as the inner bow. They were bent at an angle that would pass through the center of resistance of the maxillary first molar. The inner bows were placed into headgear tubes of slightly greater than .090 inch diameter. One two ounce, four 'ounce, and six ounce elastic at separate times were connected from each control and experimental outer bow to the horizontal sliding bar on the vertical posts of the DEFA. The units of distal crown tipping, anterior-posterior translation, transverse translation, and buccal crown tipping of the right and left maxillary molar were recorded by a crosslike indicator on a unit grid. The force generated by the three elastics were measured and recorded by an Instron Model 1130 Universal Testing Machine with a ten pound load cell at one pound full scale.

Statistical analysis ( $t$-values) were made on torqued, non-torqued, and torqued vs. non-torqued facebows for various magnitudes of force for buccal tipping and transverse translation of the maxillary right and left molar.

From the results of the statistical analysis, a force level for transverse translation of the maxillary molar was determined, and a design of a torquing highpull headgear was proposed. 


\section{CONCLUSIONS}

Based on the samples involved in this study, and the statistical analysis of this data, the following conclusions are made.

The DEFA testing facebows with a cervical and highpull direction of pull has reliable reproduceable values.

Buccal crown tipping of the maxillary right and left molar will occur at the two, four, and six ounce level with a non-torqued facebow. Transverse translation will not occur with a non-torqued facebow.

Transverse translation of the maxillary right and left molar will occur at the four and six ounce level with a torqued facebow.

The force needed for transverse translation of the maxillary first molar is 200-347 grams.

The proposed design for a torquing highpull headgear was a .045 inch inner bow with doubled over distal ends and nine degrees of buccal root torque incorporated in the doubled over distal ends. Along with this a medium outer bow bent at an angle to pass through the center of resistance of the maxillary first molar with a direction of pull from the parietal area. 


\section{BIBLIOGRAPHY}

1. Andrews, Lawrence F.: "The Six Keys to Normal Occlusion," American Journal of Orthodontics, 62:296-309, 1972.

2. Angle, Edward H.: "Some New Forms of Orthodontic Mechanism and Reasons for their Introduction," Dental Cosmos, 58:969-994, 1916.

3. Angle, Edward H.: "The Latest and Best in Orthodontic Mechanism," Dental Cosmos, 70:1143-1160, 1928.

4. Angle, Edward H.: "The Latest and Best in Orthodontic Mechanism," Dental Cosmos, $71: 260-270,1929$.

5. Angle, Edward H.: "The Latest and Best in Orthodontic Mechanism," Dental Cosmos, $71: 409-421,1929$.

6. Angle, Edward H.: Bioprogressive Therapy, Rickets, et al., Rocky Mountain Orthodontics, 1979.

7. Armstrong, Maclay M.: "Controlling the Magnitude, Direction and Duration of Extraoral Force," American Journal of Orthodontics, $59: 217-243,1971$.

8. Baldini, Giancarlo; Haack, Donald C., and Weinstein, Sam: "Bilateral Buccolingual Forces Produced by Extraoral Traction," Angle Orthodontist, $51: 301-318,1981$.

9. Barton, John J.: "Highpull Headgear versus Cervical Traction, A Cephalometric Comparison," American Journal of Orthodontics, $62: 517-529,1972$.

10. Bergersen, Earl 0.: "The Directions of Facial Growth from Infancy to Adulthood," Angle Orthodontist, 36:18-43, 1966.

11. Berman, Maurice: "Directional Forces," British Journal of Orthodontics, 3:131-137, 1976.

12. Bowden, D.E.J.: "Theoretical Considerations of Headgear Therapy:

A Literature Review," British Journal of Orthodontics, $5: 145-152,1978$.

13. Brodie, Allen G.: "An Appraisal of Present Day Orthodontic Procedure," Dental Cosmos, 69:810-815, 1927. 
14. Brodie, Allen G.: "A Discussion of Torque Force," Angle Orthodontist, 3:263-265, 1933.

15. Burstone, Charles J.: "The Biomechanics of Tooth Movement," Vistas in Orthodontics, 1962.

16. Case, Calvin: Bioprogressive Therapy, Ricketts, et al., Rocky Mountain Orthodontics, 1979.

17. Cellier, A.: Bioprogressive Therapy, Ricketts, et al., Rocky Mountain Orthodontics, 1979.

18. Chaconas, Spior J., Caputa, Angelo A., and Davis, James C.: "The Effects of Orthopedic Forces on the Craniofacial Complex Utilizing Cervical and Headgear Appliances," American Journal of Orthodontics, 69:527-539, 1976.

19. Christiansen, Richard L.: "Centers of Rotation within the Periodontal Space," American Journal of Orthodontics, 55:353-369, 1969.

20. Contasti, Gisela I., and Legan, Harry L.: "Biomechanical Guidelines for Headgear Application," Journal of Clinical Orthodontics, $16: 308-312$, 1982 .

21. Creekmore, Thomas D.: "Inhibition or Stimulation of Vertical Growth of the Facial Complex, Its Significance to Treatment," Angle Orthodontist, 37:285-297, 1967.

22. Creekmore, Thomas D.: "On Torque," Journal of Clinical Orthodontics, 13:305-316, 1979 .

23. Fish, Gilbert D.: "Some Engineering Principles of Possible Interest to the Orthodontist," Dental Cosmos, 59:881-889, 1917.

24. Goddard, G.: Bioprogressive Therapy, Ricketts, et a1., Rocky Mountain Orthodontics, 1979.

25. Gould, Eugene: "Mechanical Principles in Extraoral Anchorage," American Journal of Orthodontics, 43:379-331, 1957.

26. Graber, Thomas: Proceedings of the 1957 Cephalometric Workshop.

27. Greenspan, Ronald A.: "Reference Charts for Controlled Extraoral Force Application to Maxillary Molars," American Journal of Orthodontics, 58:486-491, 1970.

28. Guilford, M.: Bioprogressive Therapy, Ricketts, et al., Rocky Mountain Orthodontics, 1979. 
29. Harvold, Egil P.: The Activator in Interceptive Orthodontics, C.V. Mosby Co., 1974 .

30. Hickman, John H.: "Directional Edgewise Orthodontic Approach," Journal of Clinical Orthodontics, 8:617-633, 1974.

31. Hilgers, D.C., Nanda, R., Terral, J., and Aytan, S.: "Headgear, A Di lemma: Which, When, and Why," European Orthodontic Society, 47:245-253, 1971 .

32. Jacobson, Alex: "A Key to the Understanding of Extraoral Forces," American Journal of Orthodontics, 75:361-386, 1979.

33. Jarabak, Joseph: "Development of a Treatment Plan in the Light of One's Concepts of Treatment Objectives," American Journal of Orthodontics, 46:481-514, 1960 .

34. Jarabak, Joseph: Technique and Treatment with the Light Wire Appliance, C.V. Mosby Co., 1963.

35. Kingsley, Norman William: Bioprogressive Therapy, Ricketts, et al., Rocky Mountain Orthodontics, 1979.

36. Kloehn, Silas J.: "Guiding Aveolar Growth and Eruption of Teeth to Reduce Treatment Time and Produce a More Balanced Denture and Face," Angle Orthodontist, 17:10-22, 1947.

37. Kuhn, Robert J.: "Control of Anterior Vertical Dimension and Proper Selection of Extraoral Anchorage," Angle Orthodontist, $38: 340-349,1968$.

38. Lee, Brian: Bioprogressive Therapy, Ricketts, et a1., Rocky Mountain Orthodontics, 1979.

39. Lindgren, Arne and Lagerstrom, Lennart: "Facebow Testing on a Dynamic Extraoral Force Analyzer," American Journal of Orthodontics, 72:568-576, 1977.

40. McKenzie, Malcolm M.: "Ideals of the Ribbon Arch," Dental Cosmos, $69: 1051-1054,1927$.

41. Merrifield, Levern L., and Cross, James J.: "Directional Forces," American Journal of Orthodontics, 57:435-464, 1970.

42. Mitchel1, David L., and Kinder, Jack D.: "A Comparison of Two Torquing Techniques on the Maxillary Central Incisor," American Journal of Orthodontics, 63:407-419, 1973. 
43. Newcomb, Morse R.: "Some Observations of Extraoral Treatment," Angle Orthodontist, 28:131-148, 1958.

44. Nickolai, Robert J.: "An Optimum Orthodontic Force Theory as Applied to Canine Retraction," American Journal of Orthodontics, 68:290-302, 1975.

45. Oosthuizen, Len, Kijkman, J.F.P., and Evans, W.G.: "A Mechanical Appraisal of the Kloehn Extraoral Assembly," American Journal of Orthodontics, 43:221-232, 1973.

46. Oppenheim, Albin: "Tissue Changes Particularly of the Bone Incident to Tooth Movement," Angle Orthodontist, 3:57-69, 1936 .

47. Oppenheim, Albin: Bioprogressive Therapy, Ricketts, et a1., Rocky Mountain Orthodontics, 1979.

48. Poulton; Donald R.: "Changes in Class II Malocclusions With and Without Occipital Headgear Therapy," Angle Orthodontist, 29:234-246, 1959 .

49. Poulton, Donald R.: "Influence of Extraoral Traction," American Journal of Orthodontics, 53:8-19, 1967.

50. Rauch, Erman D.: "Torque and Its Application to Orthodontics," American Journal of Orthodontics, 45:817-830, 1959.

51. Ricketts, Robert M.: "Planning Treatment on the Basis of Facial Pattern and an Estimate of Its Growth," Angle Orthodontist, $27: 14-27,1957$.

52. Ricketts, Robert M.: "The Influence of Orthodontic Treatment on Facial Growth and Development," Angle Orthodontist, $30: 103-111,1960$.

53. Rusch, Jean-Pierre, and Stockli, Paul W.: "The Dynamic Extraoral Force Analyzer (DEFA)," Transactions European Orthodontic Society, 46:583-589, 1970.

54. Rusch, Jean-Pierre: Personal Communication, 1982.

55. Schrody, David W.: "A Mechanical Evaluation of Buccal Segment Reaction to Edgewise Torque," American Journal of Orthodontics, $44: 120-129,1974$.

56. Schudy, George F.: "Vertical Growth versus Anterior-Posterior Growth as Related to Function and Treatment," Angle Orthodontist, $34: 75-93,1964$. 
57. Schudy, George F.: "The Rotation of the Mandible Resulting from Growth; Its Implications in Orthodontic Treatment," Angle Orthodontist, $35: 36-50,1965$.

58. Stevenson, W.: "Extraoral Anchorage and Traction in Orthodontics," British Dental Journal, 122:309-312, 1967.

59. Strang, Robert H.: "A Definite Technique Applied to Ribbon Arch Modifications for Tooth Movement," Dental Cosmos, 67:779-796, 1925 .

60. Strang, Robert H: "Ideals in Treatment," Angle Orthodontist, $5: 29-54,1935$.

61. Sved, Alexander: "The Behavior of Archwires in Fixed Attachments," International Journal of Orthodontia, 23:683-686, 1937.

62. Thurow, Robert C.: Edgewise Orthodontics, C.V. Mosby Co., 1972.

63. Thurow, Robert C.: Edgewise Orthodontics, C.V. Mosby Co., 1982.

64. Worms, Frank W., Isaacson, Robert J., and Speide1, T. Michae1: "A Concept and Classification of Centers of Rotation and Extraoral Force Systems," Angle Orthodontist $43: 384-401,1973$. 
APPENDIX $A-1$ 
Appendix A-1

Distance of Stretch of Two Ounce Elastics on Non-torqued Facebows

\begin{tabular}{|c|c|c|c|c|c|}
\hline Facebow & rt. side (inches) & 1t. side (inches) & rt. side.(avg.) & 1t. side (avg.) & $\begin{array}{r}\text { Total } \\
\text { Avg. } \\
\end{array}$ \\
\hline A & $\begin{array}{l}2.075 \\
2.077 \\
2.064\end{array}$ & $\begin{array}{l}1.917 \\
1.940 \\
1.965\end{array}$ & 2.072 & 1.941 & 2.006 \\
\hline B & $\begin{array}{l}1.989 \\
1.972 \\
1.964\end{array}$ & $\begin{array}{l}1.956 \\
1.982 \\
1.958\end{array}$ & 1.975 & 1.965 & 1.970 \\
\hline c & $\begin{array}{l}1.993 \\
2.022 \\
2.071\end{array}$ & $\begin{array}{l}1.968 \\
1.955 \\
1.844\end{array}$ & 2.029 & 1.936 & 1.9 \\
\hline D & $\begin{array}{l}1.965 \\
1.882 \\
1.923\end{array}$ & $\begin{array}{l}1.899 \\
1.890 \\
1.882\end{array}$ & 1.923 & 1.890 & 1.9 \\
\hline$E$ & $\begin{array}{l}1.991 \\
1.985 \\
2.040\end{array}$ & $\begin{array}{l}1.998 \\
1.936 \\
1.899\end{array}$ & 2.005 & 1.944 & 1.9 \\
\hline
\end{tabular}


APPENDIX $A-2$ 


\section{Appendix A-2}

Distance of Stretch of Four Ounce Elastics on Non-torqued Facebows

\begin{tabular}{|c|c|c|c|c|c|}
\hline Facebow & rt. side (inches) & 1t. side (inches) & rt. side (avg.) & 1t. side (avg.) & $\begin{array}{r}\text { Total } \\
\text { Avg. } \\
\end{array}$ \\
\hline A & $\begin{array}{l}2.061 \\
1.974 \\
1.984\end{array}$ & $\begin{array}{l}1.885 \\
1.809 \\
1.857\end{array}$ & 2.006 & 1.850 & 1.928 \\
\hline B & $\begin{array}{l}1.825 \\
1.835 \\
1.785\end{array}$ & $\begin{array}{l}1.914 \\
1.805 \\
1.848\end{array}$ & 1.815 & 1.856 & 1.835 \\
\hline C & $\begin{array}{l}1.895 \\
1.816 \\
1.745\end{array}$ & $\begin{array}{l}1.809 \\
1.835 \\
1.899\end{array}$ & 1.819 & 1.848 & 1.833 \\
\hline D & $\begin{array}{l}1.718 \\
1.686 \\
1.700\end{array}$ & $\begin{array}{l}1.726 \\
1.682 \\
1.778\end{array}$ & 1.701 & 1.729 & 1.715 \\
\hline$E$ & $\begin{array}{l}1.739 \\
1.802 \\
1.762\end{array}$ & $\begin{array}{l}1.822 \\
1.825 \\
1.807\end{array}$ & 1.768 & 1.818 & 1.793 \\
\hline
\end{tabular}


APPENDIX A-3 
Appendix A-3

Distance of Stretch of Six Ounce Elastics on Non-torqued Facebows

\begin{tabular}{|c|c|c|c|c|c|}
\hline Facebow & rt. side (inches) & 1t. side (inches) & rt. side (avg.) & 1t. side (avg.) & $\begin{array}{l}\text { Total } \\
\text { Avg. } \\
\end{array}$ \\
\hline$A$ & $\begin{array}{l}1.715 \\
1.719 \\
1.746\end{array}$ & $\begin{array}{l}1.725 \\
1.741 \\
1.715\end{array}$ & 1.727 & 1.727 & 1.727 \\
\hline B & $\begin{array}{l}1.752 \\
1.723 \\
1.720\end{array}$ & $\begin{array}{l}1.818 \\
1.742 \\
1.804\end{array}$ & 1.732 & 1.788 & 1.760 \\
\hline C & $\begin{array}{l}1.836 \\
1.855 \\
1.824\end{array}$ & $\begin{array}{l}1.784 \\
1.763 \\
1.781\end{array}$ & 1.838 & 1.776 & 1.807 \\
\hline D & $\begin{array}{l}1.718 \\
1.703 \\
1.681\end{array}$ & $\begin{array}{l}1.655 \\
1.615 \\
1.656\end{array}$ & 1.701 & 1.642 & 1.671 \\
\hline$E$ & $\begin{array}{l}1.702 \\
1.760 \\
1.730\end{array}$ & $\begin{array}{l}1.752 \\
1.753 \\
1.732\end{array}$ & 1.731 & 1.746 & 1.739 \\
\hline
\end{tabular}


APPENDIX $\mathrm{A}-4$ 
Appendix A-4

Distance of Stretch of Two Ounce Elastics on Torqued Facebows

\begin{tabular}{|c|c|c|c|c|c|}
\hline Facebow & rt. side (inches) & 1t. side (inches) & rt. side'(avg.) & It side (avg.) & $\begin{array}{c}\text { Total } \\
\text { Avg. }\end{array}$ \\
\hline A & $\begin{array}{l}2.045 \\
2.020 \\
2.096\end{array}$ & $\begin{array}{l}1.988 \\
1.980 \\
1.930\end{array}$ & 2.054 & 1.966 & 2.010 \\
\hline B & $\begin{array}{l}1.973 \\
1.993 \\
1.960\end{array}$ & $\begin{array}{l}1.930 \\
1.918 \\
1.914\end{array}$ & 1.975 & 1.921 & 1.948 \\
\hline C & $\begin{array}{l}2.047 \\
2.079 \\
2.055\end{array}$ & $\begin{array}{l}1.920 \\
1.986 \\
1.989\end{array}$ & 2.060 & 1.965 & 2.012 \\
\hline$D$ & $\begin{array}{l}1.948 \\
1.898 \\
1.956\end{array}$ & $\begin{array}{l}1.925 \\
1.896 \\
1.901\end{array}$ & 1.934 & 1.907 & 1.921 \\
\hline$E$ & $\begin{array}{l}1.996 \\
1.936 \\
1.976\end{array}$ & $\begin{array}{l}1.928 \\
1.996 \\
1.992\end{array}$ & 1.969 & 1.972 & 1.971 \\
\hline
\end{tabular}


APPENDIX A-5 
Appendix A-5

Distance of Stretch of Four Ounce Elastics on Torqued Facebows

\begin{tabular}{|c|c|c|c|c|c|}
\hline Facebow & rt. side (inches) & 1t. side (inches) & rt. side (avg.) & It side (avg.) & $\begin{array}{r}\text { Total } \\
\text { Avg. } \\
\end{array}$ \\
\hline$A$ & $\begin{array}{l}2.064 \\
1.991 \\
1.997\end{array}$ & $\begin{array}{l}1.957 \\
1.943 \\
1.955\end{array}$ & 2.017 & 1.952 & 1.984 \\
\hline$B$ & $\begin{array}{l}1.894 \\
1.829 \\
1.856\end{array}$ & $\begin{array}{l}1.814 \\
1.845 \\
1.836\end{array}$ & 1.860 & 1.832 & 1.846 \\
\hline C & $\begin{array}{l}1.886 \\
1.852 \\
1.848\end{array}$ & $\begin{array}{l}1.898 \\
1.828 \\
1.872\end{array}$ & 1.862 & 1.866 & 1.864 \\
\hline D & $\begin{array}{l}1.757 \\
1.762 \\
1.713\end{array}$ & $\begin{array}{l}1.719 \\
1.780 \\
1.728\end{array}$ & 1.744 & 1.742 & 1.743 \\
\hline$E$ & $\begin{array}{l}1.739 \\
1.782 \\
1.770\end{array}$ & $\begin{array}{l}1.781 \\
1.800 \\
1.804\end{array}$ & 1.764 & 1.795 & 1.780 \\
\hline
\end{tabular}


APPENDIX A-6 


\section{Appendix A-6}

Distance of Stretch of Six Ounce Elastics on Torqued Facebows

\begin{tabular}{|c|c|c|c|c|c|}
\hline Facebow & rt. side (inches) & 1t. side (inches) & rt. side (avg.) & It side (avg.) & $\begin{array}{r}\text { Total } \\
\text { Avg. } \\
\end{array}$ \\
\hline$A$ & $\begin{array}{l}1.745 \\
1.739 \\
1.764\end{array}$ & $\begin{array}{l}1.732 \\
1.741 \\
1.739\end{array}$ & 1.749 & 1.737 & 1.743 \\
\hline B & $\begin{array}{l}1.748 \\
1.731 \\
1.752\end{array}$ & $\begin{array}{l}1.783 \\
1.754 \\
1.791\end{array}$ & 1.744 & 1.776 & 1.760 \\
\hline C & $\begin{array}{l}1.788 \\
1.792 \\
1.799\end{array}$ & $\begin{array}{l}1.765 \\
1.795 \\
1.783\end{array}$ & 1.793 & 1.780 & 1.787 \\
\hline D & $\begin{array}{l}1.728 \\
1.715 \\
1.704\end{array}$ & $\begin{array}{l}1.701 \\
1.699 \\
1.693\end{array}$ & 1.716 & 1.698 & 1.707 \\
\hline$E$ & $\begin{array}{l}1.722 \\
1.741 \\
1.747\end{array}$ & $\begin{array}{l}1.743 \\
1.724 \\
1.739\end{array}$ & 1.737 & 1.735 & 1.736 \\
\hline
\end{tabular}




\section{APPENDIX $A-7$}




\section{Appendix A-7}

Units of Tooth Movements With Facebows of Zero Torque and Two Ounce Elastics

\begin{tabular}{|c|c|c|c|c|c|c|c|c|}
\hline & & & & & 8,1 & & & \\
\hline$A$ & 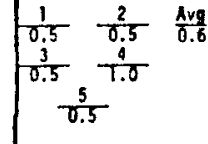 & $\begin{array}{ll}\frac{1}{0.5} & \frac{2}{0.5} \\
\frac{3.5}{0.5} & \frac{4.9 .}{0.5} \\
\frac{5.5}{0.5} & \end{array}$ & $\begin{array}{lll}\frac{1}{0.5} & \frac{2}{0.0} & \text { Avg. } \\
\frac{0}{0.0} & \frac{0}{0.0} \\
\frac{0.0}{0.0} & \end{array}$ & $\begin{array}{l}\frac{1}{0.0} \frac{2}{0.0} \frac{\text { Avg. }}{0.0} \\
\frac{0}{0.0} \frac{\frac{1}{0.0}}{0.0} \\
\frac{.5}{0.0}\end{array}$ & 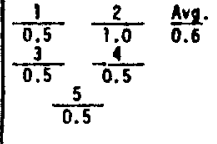 & $\begin{array}{l}\frac{1}{0.5} \frac{2}{0.5} \frac{\text { Avg. }}{0.5} \\
\frac{0.5}{0.5} \frac{T^{0.5}}{0.5} \\
\frac{5}{0.5}\end{array}$ & $\begin{array}{l}\frac{1}{0.0} \frac{2}{0.0} \frac{\text { Avg. }}{0.0} \\
\frac{3.0}{0.0} \frac{\frac{4}{0.0}}{\frac{0.0}{0.0}}\end{array}$ & 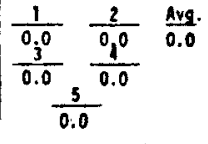 \\
\hline & $\int_{\frac{3}{3.0}}^{\frac{5}{1.0}} \frac{\frac{1.0}{1.0}}{1.0}$ & $\frac{\frac{1}{1.0}}{\frac{3}{1.0}} \frac{\frac{2}{1.0}}{\frac{6}{0.5}} \frac{\text { Avg. }}{0.0}$ & 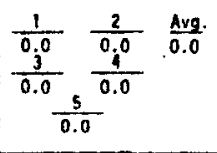 & $\frac{\frac{1}{0.0}}{\frac{3}{0.0}} \frac{\frac{2}{0.0}}{\frac{5}{0.0}} \frac{\frac{\mathrm{Avg}}{0.0}}{0.0}$ & $\underbrace{\frac{1}{0.5}} \frac{\frac{2}{1.0}}{\frac{3}{1.0}} \frac{\frac{\mathrm{Avg} .}{0.9}}{\frac{5}{1.0}}$ & $\begin{array}{l}\frac{1}{0.5} \frac{2}{1.0} \frac{\mathrm{Avg}}{0.0} \\
\frac{3}{1.0} \frac{4}{1.0} \\
\frac{5}{1.0}\end{array}$ & $\begin{array}{l}\frac{1}{0.3} \frac{2}{\frac{3}{0.0}} \\
\frac{\frac{\mathrm{Avg}}{0.0}}{0.1} \\
\frac{5}{0.0}\end{array}$ & $\frac{1}{\frac{0.0}{0.0}} \frac{\frac{2}{0.0}}{\frac{5}{0.0}} \frac{\frac{\text { Avg. }}{0.0}}{0.0}$ \\
\hline & $\begin{array}{ll}\frac{1}{0.5} & \frac{2}{0.5} \\
\frac{3}{3.5} & \frac{4}{0.6} \\
\frac{0.5}{1.0 .5} & \frac{5}{0.5}\end{array}$ & 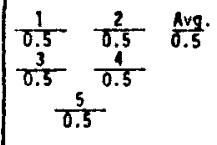 & $\begin{array}{l}\frac{1}{0.0} \frac{2}{0.0} \frac{\text { Avg. }}{0.0} \\
\frac{3}{0.0} \frac{\frac{4}{0.0}}{\frac{5}{0.0}}\end{array}$ & $\begin{array}{l}\frac{1}{\frac{0.0}{0.0}} \frac{2}{\frac{3}{0.0}} \frac{\mathrm{Avg}}{0.0} \\
\frac{10.0}{0.0} \frac{\frac{1}{0.0}}{0.0}\end{array}$ & $\frac{\frac{1}{0.5}}{\frac{\frac{1}{0.5}}{\frac{0.5}{\frac{5}{0.0}}} \frac{\frac{\mathrm{Avg}}{0.5}}{0.5}}$ & $\begin{array}{l}\frac{1}{0.5} \frac{2}{0.5} \\
\frac{3.5}{0.5} \frac{1}{0.5} \\
\frac{0.5}{0.5}\end{array}$ & $\begin{array}{l}\frac{1}{0.0} \frac{2}{0.0} \frac{\text { Avg. }}{0.0} \\
\frac{3}{0.0} \frac{i}{0.0} \\
\frac{-5}{0.0}\end{array}$ & $\begin{array}{l}\frac{1}{0.0} \frac{2}{\frac{j}{0.0}} \frac{\text { Avg. }}{0.0} \\
\frac{\frac{1}{0.0}}{0.0} \\
\frac{0.0}{0.0}\end{array}$ \\
\hline & $\begin{array}{l}\frac{1}{0.5} \frac{2}{0.5} \\
\frac{3}{0.5} \\
\frac{0.5}{0.5} \\
\frac{5}{0.5} \\
\frac{0.5}{0.5}\end{array}$ & $\begin{array}{l}\frac{1}{0.5} \frac{2}{0.5} \frac{\text { Avg. }}{0.6} \\
\frac{3}{0.5}, \frac{1}{1.0} \\
\frac{5}{0.5}\end{array}$ & $\begin{array}{l}\frac{1}{0.0} \frac{2}{0.0} \frac{\text { Avg. }}{0.0} \\
\frac{3}{0.0} \frac{\frac{4}{0.0}}{\frac{5.0}{0.0}}\end{array}$ & $\begin{array}{l}\frac{1}{0.0} \frac{2}{0.0} \frac{\mathrm{Avg} .}{0.0} \\
\frac{\frac{3}{0.0}}{\frac{0.0}{0.0}} \\
\frac{5.0}{0.0}\end{array}$ & 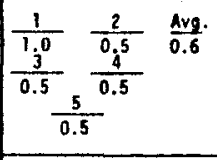 & $\begin{array}{l}\frac{1}{1.0} \frac{2}{0.5} \frac{\text { Avg. }}{0.6} \\
\frac{3}{0.5} \frac{4}{0.5} \\
\frac{5.5}{0.5} .\end{array}$ & $\frac{\frac{1}{0.0}}{\frac{0 .}{\frac{0}{0.0}}} \frac{\frac{2}{0.0}}{\frac{\text { Avg. }}{0.0}}$ & $\frac{\frac{1}{0.0}}{\frac{0.0}{0.0}} \frac{\frac{2}{0.0}}{\frac{1}{0.0}} \frac{\text { Avg. }}{0.0}$ \\
\hline & $\begin{array}{cc}\frac{1}{1.0} & \frac{2}{1.0} \\
\frac{3}{1.0} & \frac{4}{1.0} \\
\frac{5.5}{0.5} & \frac{1}{0.5}\end{array}$ & $\begin{array}{c}\frac{1}{1.0} \frac{2}{\frac{1}{1.0}} \frac{\text { Avg. }}{1.0} \\
\frac{3}{1.0} \frac{4}{1.0} \\
\frac{5}{1.0}\end{array}$ & $\begin{array}{l}\frac{1}{\frac{0.0}{0.0}} \frac{2}{\frac{0}{0.0}} \frac{\text { Avg. }}{0.0} \\
\frac{3}{0.0} \frac{\frac{4}{0.0}}{\frac{5}{0.0}} \\
\frac{1}{0.0}\end{array}$ & $\begin{array}{l}\frac{1}{0.0} \frac{2}{0.0} \frac{\text { Avg. }}{0.0} \\
\frac{3}{0.0} \frac{i}{0.0} \\
\frac{5.5}{0.0} \\
\end{array}$ & $\frac{\frac{1}{0.5}}{\frac{3}{\frac{3}{1.0}} \frac{\frac{2}{1.0}}{\frac{4}{1.0}}} \frac{\frac{4}{1.0}}{0.9}$ & $\begin{array}{l}\frac{1}{1.0} \frac{2}{1.0} \\
\frac{3}{1.0} \frac{4.9}{1.0} \\
\frac{5}{1.0}\end{array}$ & 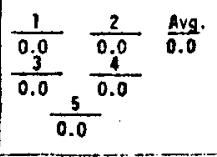 & $\frac{1}{\frac{1}{0.0}} \frac{2}{\frac{3}{0.0}}$ \\
\hline
\end{tabular}


APPENDIX $A-8$ 
Appendix A-8

Units of Tooth Movements With Facebows of Zero Torque and Four Ounce Elastics

\begin{tabular}{|c|c|c|c|c|c|c|c|c|}
\hline & 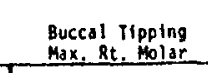 & 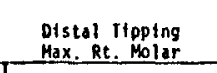 & $\begin{array}{l}\text { Max. Rt. Hol } \\
\text { Hel }\end{array}$ & 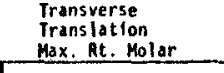 & $\begin{array}{l}\text { Buccal Thpong } \\
\text { Max. Lt. Molar }\end{array}$ & $\begin{array}{l}\text { Distal Tipping } \\
\text { Max. Lt. Holar }\end{array}$ & & 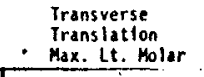 \\
\hline 1 & 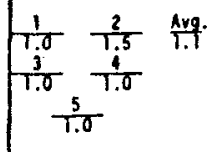 & $\begin{array}{l}\frac{1}{0.5} \frac{2}{1.0} \frac{\text { Avg. }}{0.9} \\
\frac{3}{1.0} \frac{\frac{4}{1.0}}{1.0} \\
\frac{5}{1.0}\end{array}$ & $\begin{array}{l}\frac{1}{0.5} \frac{2}{0.5} \\
\frac{3}{0.5} \frac{\frac{1}{0.5} .}{0.5} \\
\frac{5}{0.5}\end{array}$ & $\begin{array}{ll}\frac{1}{0.0} & \frac{2}{0.0} \\
\frac{3}{0.0} & \frac{1}{0.0 .} \\
\frac{0.0}{0.0} & \frac{5}{0.0}\end{array}$ & $\begin{array}{l}\frac{1}{1.0} \frac{2}{1.0} \frac{\text { Avg. }}{1.0} \\
\frac{1.0}{1.0} \frac{4}{1.0} \\
\frac{5}{1.0}\end{array}$ & $\frac{\frac{1}{1.0}}{\frac{3}{1.0}} \frac{\frac{2}{0.5}}{\frac{1}{1.0}} \frac{\text { Avg. }}{0.9}$ & $\begin{array}{l}\frac{1}{0.5} \\
\frac{3}{1.0} \frac{\frac{2}{0.5}}{\frac{5.5}{0.5}} \\
\frac{\frac{\mathrm{Avg}}{0.6}}{0.5}\end{array}$ & $\frac{\frac{1}{0.0}}{\frac{0.0}{0.0}} \frac{\frac{2}{0.0}}{\frac{0.0}{0.0}} \frac{\text { Avg }}{0.0}$ \\
\hline 8 & 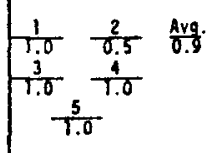 & $\begin{array}{l}\frac{1}{1.0} \frac{2}{1.0} \\
\frac{3}{1.0} \frac{4}{1.0} \\
\frac{5}{1.0}\end{array}$ & $\begin{array}{l}\frac{1}{0.5} \frac{2}{0.5} \frac{\text { Avg. }}{0.5} \\
\frac{j}{0.5} \frac{\frac{4}{0.5}}{\frac{5}{0.5}} \\
\frac{0}{0.5}\end{array}$ & $\begin{array}{l}\frac{1}{0.0} \frac{2}{0.0} \\
\frac{3}{0.0} \frac{\frac{4}{0.9}}{0.0} \\
\frac{\frac{5}{0.0}}{0.0}\end{array}$ & $\begin{array}{l}\frac{1}{0.5} \frac{2}{1.0} \frac{\text { Avg. }}{\frac{3}{0.9}} \\
\frac{4}{1.0} \frac{\frac{4}{1.0}}{10 .}\end{array}$ & $\begin{array}{l}\frac{1}{0.5} \frac{2}{1.0} \frac{\mathrm{Avg} .}{0.9} \\
\frac{3}{1.0} \frac{\frac{1}{1.0}}{1.0} \\
\frac{1.0}{1.0}\end{array}$ & $\frac{\frac{1}{0.5}}{\frac{3}{0.5}} \frac{\frac{2}{0.5}}{\frac{4}{0.5}} \frac{\frac{\text { Avg. }}{0.5}}{0.5}$ & $\frac{\frac{1}{0.0}}{\frac{3}{0.0}} \frac{\frac{2}{0.0}}{\frac{5}{0.0}} \frac{\text { Avg }}{0.0}$ \\
\hline${ }^{8}$ & 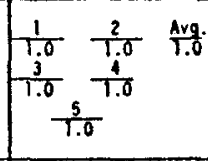 & $\begin{array}{lll}\frac{1}{1.0} & \frac{2}{0.5} & \text { Avg. } \\
\frac{3}{1.9} & \frac{1}{1.0} \\
\frac{5}{1.0} & \\
\frac{5}{1.0} & \end{array}$ & $\begin{array}{lll}\frac{1}{1.0} & \frac{2}{0.5} & \text { Avg. } \\
\frac{3}{0.5} & \frac{6}{0.5} \\
\frac{0.5}{0.5} & \frac{5}{0.5}\end{array}$ & $\begin{array}{c}\frac{1}{0.0} \frac{2}{\frac{3}{0.0}} \frac{\text { Avg. }}{0.0} \\
\frac{3}{0.0} \frac{\frac{1}{0.0}}{\frac{5}{0.0}} \\
\frac{0}{0.0}\end{array}$ & $\begin{array}{lll}\frac{1}{1.0} & \frac{2}{0.5} & \frac{\text { Avg. }}{0.9} \\
\frac{3}{1.0} & \frac{4}{1.0} \\
\frac{5}{1.0} & \end{array}$ & $\begin{array}{c}\frac{1}{0.5} \frac{2}{1.0} \\
\frac{30.9}{0.9} \\
\frac{3}{1.0} \frac{4}{1.0} \\
\frac{5}{1.0} \\
\end{array}$ & $\begin{array}{l}\frac{1}{0.5} \\
\frac{3}{0.5} \frac{\frac{2}{1.0}}{\frac{1}{0.5}} \\
\frac{4}{0.5}\end{array}$ & $\frac{\frac{1}{0.0}}{\frac{3}{0.0}} \frac{\frac{2}{0.0}}{\frac{5}{0.0}} \frac{\text { Avg. }}{0.0}$ \\
\hline & $\begin{array}{l}\frac{1}{\frac{1}{1.0}} \frac{2}{1.0} \\
\frac{\text { Avg. }}{1.0} \\
\frac{4}{1.0} \frac{5}{1.0} \\
\frac{5.0}{1.0}\end{array}$ & $\begin{array}{c}\frac{1}{1.5} \frac{2}{1.0} \text { Avg. } \\
\frac{j}{1.0} \frac{4}{1.0} \\
\frac{5}{1.0}\end{array}$ & $\begin{array}{l}\frac{1}{0.5} \frac{2}{0.5} \frac{\text { Avg. }}{0.5} \\
\frac{3}{0.5} \frac{\frac{1}{0.5}}{\frac{5}{0.5}} \\
\frac{0.5}{0.5}\end{array}$ & 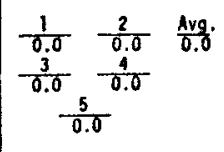 & $\mid \begin{array}{ccc}\frac{1}{1.0} & \frac{2}{1.5} & \text { Avg. } \\
\frac{3}{1.0} & \frac{4}{1.0} & \\
\frac{5}{1.0} & \frac{5}{1.0}\end{array}$ & $\begin{array}{l}\frac{1}{1.0} \frac{2}{1.0} \frac{\mathrm{Avg}}{1.0} \\
\frac{3}{1.0} \frac{\frac{1}{1.0}}{\frac{5}{1.0}}\end{array}$ & 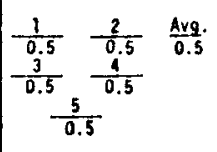 & 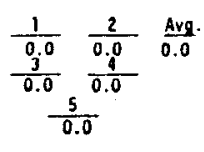 \\
\hline ⿷ & $\begin{array}{l}\frac{1}{\frac{1}{3}} \frac{\frac{2}{7.0}}{\frac{A}{1.0}} \\
\frac{\frac{4}{1.0}}{1.0} \\
\frac{5}{1.0}\end{array}$ & 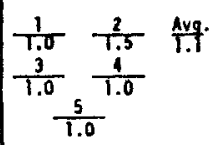 & $\begin{array}{l}\frac{1}{0.5} \frac{2}{0.5} \frac{\text { Avg. }}{0.5} \\
\frac{j}{0.5} \frac{\frac{4}{0.5}}{0.5}\end{array}$ & $\begin{array}{l}\frac{1}{0.0} \frac{\frac{2}{0.0}}{\frac{3}{0.0}} \\
\frac{\frac{4}{0.0}}{0.0} \frac{5}{0.0}\end{array}$ & $\mid \begin{array}{l}\frac{1}{1.0} \frac{2}{1.0} \text { Avg. } \\
\frac{3}{1.0} \frac{\frac{4}{1.0}}{\frac{5}{1.0}}\end{array}$ & $\begin{array}{l}\frac{\frac{1}{1.0}}{\frac{3}{1.0}} \frac{\frac{2}{1.0}}{\frac{1}{1.0}} \frac{\text { Avg. }}{1.0} \\
\frac{5}{1.0}\end{array}$ & $\begin{array}{l}\frac{\frac{3}{1.0}}{\frac{3}{0.5}} \frac{2}{0.9 .9} \\
\frac{\frac{1}{0.5}}{0.5} \frac{\frac{1}{0.5}}{\frac{0.5}{0.5}}\end{array}$ & $\begin{array}{c}\frac{1}{0.0} \frac{2}{0.0} \frac{\text { Avg. }}{0.0} \\
\frac{3}{0.0} \frac{\frac{4}{0.0}}{0.0} \\
\frac{5}{0.0}\end{array}$ \\
\hline
\end{tabular}


APPENDIX A-9 
Appendix A-9

Units of Tooth Movements of Facebows WIth Zero Torque and Six Ounce Elastics

\begin{tabular}{|c|c|c|c|c|c|c|c|c|}
\hline acesow & $\begin{array}{l}\text { Buccal "pping } \\
\text { Max. Rt, tholar }\end{array}$ & & 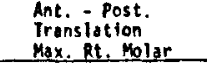 & Molar & & & & ofoler \\
\hline A & $\begin{array}{l}\frac{1}{\frac{1}{3}} \frac{\frac{2}{1.5}}{\frac{i}{3}} \\
\frac{\text { Avg. }}{1.5}, \frac{1.5}{1.5} \\
\frac{5}{7.5}\end{array}$ & $\begin{array}{l}\frac{\frac{1}{1.0}}{\frac{3}{1.0}} \frac{2}{1.0} \frac{1}{0.9} \\
\frac{1}{1.0} \frac{-5}{0.5} \\
\frac{5}{1.0}\end{array}$ & $\begin{array}{l}\frac{1}{1.0} \frac{2}{\frac{1}{3}} \text { Avg. } \\
\frac{9}{1.0} \frac{1}{1.0} \\
\frac{5}{1.0}\end{array}$ & $\begin{array}{l}\frac{1}{0.0} \frac{2}{0.0} \frac{\text { Avg. }}{0.0} \\
\frac{3}{0.0} \frac{\frac{1}{0.0}}{\frac{5}{0.0}}\end{array}$ & $\begin{array}{l}\frac{1}{2.0} \frac{2}{1.5} \frac{\text { Avg. }}{1.6} \\
\frac{1}{1.5} \frac{4}{1.5} \\
\frac{5}{1.5}\end{array}$ & $\frac{\frac{1}{1.0}}{\frac{3}{1.0} \frac{2}{1.0}} \frac{\text { Avg. }}{\frac{5}{1.0}}$ & 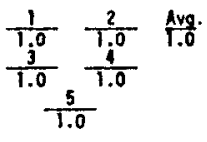 & $\begin{array}{l}\frac{1}{0.0} \frac{2}{0.0} \text { evg. } \\
\frac{3}{0.0} \frac{i .0}{0.0} \\
\frac{5}{0.0}\end{array}$ \\
\hline 8 & $\begin{array}{l}\frac{1}{\frac{1.5}{3}} \frac{2}{1.5} \text { Avg. } \\
\frac{4.5}{1.5} \frac{1.5}{7.5} \\
\frac{5}{7.5}\end{array}$ & $\begin{array}{l}\frac{1}{7.0} \frac{2}{1.0} \text { Ave. } \\
\frac{i}{1.0} \frac{1.0}{1.0} \\
\frac{5.0}{1.0}\end{array}$ & $\begin{array}{l}\frac{1}{0.5} \frac{2}{1.0} \\
\frac{3}{1.0} \frac{4}{1.0} \\
\frac{5.0}{1.0}\end{array}$ & $\begin{array}{l}\frac{1}{0.0} \frac{2}{0.0} \text { Avg. } \\
\frac{3.0}{0.0} \frac{i}{0.0} \\
\frac{5.0}{0.0}\end{array}$ & $\begin{array}{l}\frac{1}{1.5} \frac{2}{1.5} \\
\frac{1}{1.5} \\
\frac{4}{1.5} \frac{4}{1.5} \\
\frac{5}{1.5}\end{array}$ & $\begin{array}{l}\frac{1}{1.0} \frac{2}{0.5} \frac{\mathrm{Avg}}{0.9} \\
\frac{3.0}{\frac{1}{1.0}} \frac{\frac{5}{1.0}}{1.0}\end{array}$ & $\begin{array}{l}\frac{1}{1.5} \frac{2}{1.0} \text { Avg. } \\
\frac{3}{1.0} \frac{4}{1.0} \\
\frac{5}{1.0}\end{array}$ & $\begin{array}{l}\frac{\frac{1}{0.0}}{\frac{3}{3}} \frac{2}{0.0} \text { Avg. } \\
\frac{1}{0.0} \frac{5}{0.0} \\
\frac{5.0}{0.0}\end{array}$ \\
\hline c & \begin{tabular}{|l}
$\frac{1}{1.5} \frac{\frac{2}{3}}{\frac{1.5}{1.6}}$ \\
$\frac{\frac{5}{1.5}}{1.5}$ \\
$\frac{1.59}{1.5}$
\end{tabular} & $\begin{array}{l}\frac{\frac{1}{1.0}}{\frac{j}{1.0}} \frac{\frac{2}{1.0}}{1.0} \\
\frac{\text { Avg. }}{1.0} \\
\frac{5}{1.0}\end{array}$ & $\frac{\frac{1}{1.0} \frac{2}{0.5}}{\frac{i^{5}}{1.0} \frac{4}{1.0}} \frac{\text { Avg. }}{\frac{5}{1.0}}$ & $\frac{\frac{1}{0.0}}{\frac{3}{0.0}} \frac{\frac{2}{0.0}}{\frac{5}{0.0}} \frac{\text { Avg. }}{0.0}$ & $\frac{\frac{1}{\frac{1}{f^{5}}}}{\frac{1.5}{1.5}} \frac{\frac{2}{1.4^{5}}}{\frac{5}{1.5}} \frac{\text { Avg. }}{1.5}$ & $\frac{\frac{1}{1.0}}{\frac{3}{1.0}} \frac{\frac{2}{1.0}}{\frac{5}{1.0}}=\frac{\mathrm{Avg}}{1.0}$ & $\begin{array}{l}\frac{\frac{1}{1.0}}{\frac{3}{1.0}} \frac{2}{1.0} \\
\frac{\text { Avg. }}{1.0} \frac{\frac{4}{1.0}}{1.0}\end{array}$ & $\begin{array}{lll}\frac{1}{0.0} & \frac{2}{6.0} & \text { Avg. } \\
\frac{3}{0.0} & \frac{1}{0.0} \\
\frac{5}{0.0} & \end{array}$ \\
\hline 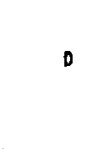 & 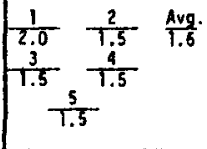 & $\begin{array}{l}\frac{1}{\frac{1}{3}} \frac{\frac{2}{1.0}}{\frac{\text { Avg. }}{1.0}} \\
\frac{\frac{1}{1.0}, \frac{5}{1.0}}{\frac{1.0}{1.0}}\end{array}$ & $\frac{\frac{1}{1.0}}{\frac{j}{1.0} \frac{\frac{2}{1.0}}{\frac{5}{1.0}}} \frac{\text { Avg. }}{1.0}$ & $\begin{array}{l}\frac{\frac{1}{0.0}}{\frac{j}{0.0}} \frac{\frac{2}{0.0}}{0.0} \\
\frac{5.0}{0.0}\end{array}$ & $\frac{\frac{1}{1.5} \frac{2}{\frac{3}{3}}}{\frac{i^{0}}{1.5}} \frac{\text { Avg. }}{1.6}$ & $\begin{array}{l}\frac{1}{1.0} \frac{2}{\frac{1}{1.0}} \text { Avg. } \\
\frac{1.0}{1.0} \frac{\frac{1}{1.0}}{\frac{5.0}{1.0}}\end{array}$ & $\begin{array}{l}\frac{1}{1.0} \frac{2}{1.0} \text { Avg. } \\
\frac{3}{1.0} \frac{i}{1.0} \\
\frac{5}{1.0}\end{array}$ & $\begin{array}{l}\frac{1}{0.0} \frac{2}{0.0} \quad \text { Avg. } \\
\frac{3}{0.0} \frac{i}{0.0} \\
\frac{5.0}{0.0}\end{array}$ \\
\hline $\mathbf{E}$ & $\frac{\frac{1}{1.5} \frac{\frac{2}{1.5}}{\frac{4}{1.5}}}{\frac{\text { Avg. }}{1.5} \frac{\frac{5}{1.5}}{\frac{5.5}{1.5}}}$ & $\begin{array}{l}\frac{1}{1.0} \quad \frac{2}{0.5} \text { ovg. } \\
\frac{3}{3.0} \frac{1}{1.0} \\
\frac{5.0}{7.0}\end{array}$ & $\frac{\frac{1}{1.0}}{\frac{3}{T .0}} \frac{\text { Avg. }}{1.0}$ & $\begin{array}{l}\frac{1}{0.0} \frac{2}{0.0} \frac{10.9}{0.0} \\
\frac{3}{0.0} \frac{\frac{4}{0.0}}{\frac{5}{0.0}}\end{array}$ & $\begin{array}{l}\frac{1}{1.5} \frac{2}{1.5} \text { Avg. } \\
\frac{3}{3.5} \frac{1}{1.5} \\
\frac{5}{1.5}\end{array}$ & $\frac{\frac{1}{1.0} \frac{2}{\frac{j}{1.0}}}{\frac{1}{1.0} \frac{\text { avg. }}{1.0}} \frac{\frac{1}{1.0}}{\frac{1.0}{1.0}}$ & $\begin{array}{l}\frac{1}{1.0} \frac{2}{1.0} \text { Avg. } \\
\frac{3}{1.0, \frac{4}{1.0}} \\
\frac{5}{1.0}\end{array}$ & $\begin{array}{l}\frac{1}{0.0} \frac{2}{0.0} \text { evg. } \\
\frac{3.0}{0.0} \frac{\frac{1}{0.0}}{\frac{5}{0.0}}\end{array}$ \\
\hline
\end{tabular}


APPENDIX A-10 
Appendix A-10

Units of Tooth Movements With Facebows of Nine Degrees Torque and Two ounce Elastics

\begin{tabular}{|c|c|c|c|c|c|c|c|c|}
\hline & & & & & ng & If & & \\
\hline A & $\mid \begin{array}{l}\frac{1}{\frac{1}{1.0}} \frac{2}{0.5} \frac{\text { Avg. }}{0.6} \\
\frac{i^{0.5}}{0.5} \\
\frac{5}{0.5}\end{array}$ & $\begin{array}{l}\frac{1}{\frac{1}{1.0}}-\frac{2}{1.0} \text { Avg. } \\
\frac{j}{1.0} \frac{i^{1.0}}{1.0} \\
\frac{5}{T .0}\end{array}$ & $\begin{array}{l}\frac{1}{0.0} \frac{2}{0.0} \frac{\text { Avg. }}{0.0} \\
\frac{j}{0.0} \frac{\frac{4}{0.0}}{\frac{5}{0.0}}\end{array}$ & $\begin{array}{l}\frac{1}{0.0} \frac{2}{\frac{0}{0.0}} \frac{\text { Avg. }}{0.0} \\
\frac{j}{0.0} \frac{\frac{i}{0.0}}{0.0} \\
\frac{0.0}{0.0}\end{array}$ & $\begin{array}{l}\frac{1}{0.5} \frac{2}{\frac{3}{1.0}} \frac{\text { Avg. }}{0.6} \\
\frac{3.5}{0.5} \frac{5}{0.5} \\
\frac{0.5}{10}\end{array}$ & $\begin{array}{l}\frac{1}{1.5} \frac{2}{\frac{3}{1.0}} \frac{\text { Avg }}{1.1} \\
\frac{1.0}{1.0} \frac{5}{1.0}\end{array}$ & $\begin{array}{l}\frac{1}{0.0} \frac{2}{0.0} \frac{\text { Avg. }}{0.0} \\
\frac{3}{0.0} \frac{5}{0.0} \\
\frac{5.0}{0.0}\end{array}$ & $\int_{\frac{1}{0.0} \frac{2}{0.0} \frac{\frac{1}{0.0}}{0.0}}^{\frac{5}{0.0}}$ \\
\hline 8 & 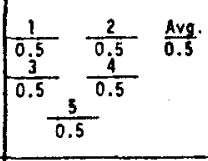 & 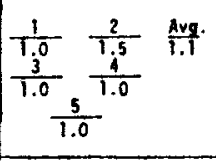 & $\begin{array}{lll}\frac{1}{0.0} & \frac{2}{0.0} & \frac{A v g .}{0.0} \\
\frac{3}{0.0} & \frac{5}{0.0} \\
\frac{10.0}{0.0} & \end{array}$ & $\begin{array}{c}\frac{1}{\frac{0.0}{0.0}} \frac{2}{0.0} \frac{\mathrm{Avg}}{0.0} \\
\frac{3}{0.0} \frac{\frac{4}{0.0}}{0.0} \\
\frac{5.0}{0.0}\end{array}$ & $\begin{array}{c}\frac{1.5}{0.5} \frac{i}{0.5} \\
\frac{3}{0.5} \frac{i}{0.5} \\
\frac{5}{0.5} \\
\frac{0.5}{0.5}\end{array}$ & $\begin{array}{c}\frac{1.0}{3} \frac{4}{1.0} \\
\frac{5}{1.0} \\
\frac{5}{1.0}\end{array}$ & 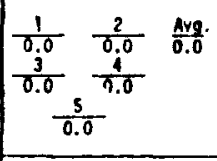 & $\begin{array}{c}\frac{1}{\frac{0.0}{0.0}} \frac{\frac{2}{0.0}}{\frac{3}{0.0}} \frac{\frac{4}{0.0}}{0.0} \\
\frac{5}{0.0} \\
0.0\end{array}$ \\
\hline 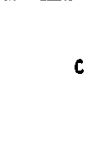 & \begin{tabular}{|lll}
$\frac{1}{0.5}$ & $\frac{2}{0.5}$ & Aveg. \\
$\frac{3}{0.5}$ & $\frac{4}{0.5}$ \\
$\frac{0.5}{0.5}$ & $\frac{5}{0.5}$ \\
$\frac{0.5}{0.5}$
\end{tabular} & 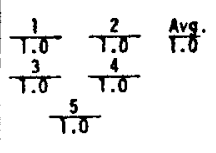 & $\begin{array}{l}\frac{1}{0.0} \frac{2}{0.0} \\
\frac{3}{0.0} \frac{A_{0.9}}{0.0} \\
\frac{5.0}{0.0} \\
\frac{5.0}{0.0}\end{array}$ & $\begin{array}{l}\frac{1}{0.0} \frac{2}{0.0} \frac{A v .8}{0.9} \\
\frac{3}{0.0} \frac{4}{0.0} \\
\frac{5.0}{0.0}\end{array}$ & $\begin{array}{l}\frac{1}{\frac{1}{3}} \frac{\frac{2}{0.5}}{\frac{\text { Avg. }}{0.6}} \\
\frac{t^{0.5}}{\frac{5.5}{0.5}}\end{array}$ & $\begin{array}{c}\frac{1.5}{3.0} \cdot 7 \\
\frac{1}{1.0}, \frac{1}{7.0} \\
\frac{5}{1.0}\end{array}$ & 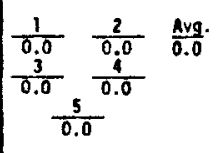 & 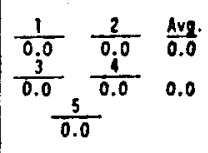 \\
\hline & 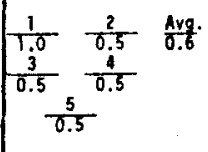 & $\begin{array}{l}\frac{1}{T .5} \frac{2}{1.0} \\
\frac{3}{3.0} \\
\frac{1}{1.09} \\
\frac{5}{1.0}\end{array}$ & $\begin{array}{l}\frac{1}{0.0} \frac{2}{0.0} \frac{\text { Avg. }}{0.0} \\
\frac{3}{0.0} \frac{\frac{4}{0.0}}{\frac{5}{0.0}}\end{array}$ & $\begin{array}{l}\frac{1}{0.0} \frac{2}{0.0} \frac{\text { Avg. }}{\frac{j}{0.0}} \frac{\frac{4}{0.0}}{\frac{0.0}{0.0}} \\
\frac{5.0}{0.0}\end{array}$ & $\begin{array}{l}\frac{1}{0.5} \frac{2}{0.5} \frac{\text { Avg. }}{0.5} \\
\frac{3}{0.5} \frac{\frac{1}{0.5}}{0.5} \\
\frac{5}{0.5}\end{array}$ & $\begin{array}{l}\frac{1}{1.0} \frac{2}{1.0} \\
\frac{3}{1.0} \frac{A_{0}}{1.0} \\
\frac{5}{1.0}\end{array}$ & $\begin{array}{l}\frac{1}{0.0} \frac{2}{0.0} \frac{\text { Avg. }}{0.0} \\
\frac{1}{0.0} \frac{\frac{1}{0.0}}{0.0} \\
\frac{5.0}{0.0}\end{array}$ & $\frac{\frac{1}{0.0}}{\frac{3}{0.0}} \frac{\frac{2}{0.0}}{\frac{5}{0.0}} \frac{\frac{\mathrm{Avg} .}{0.0}}{0.0}$ \\
\hline & 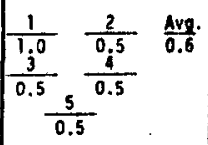 & $\begin{array}{l}\frac{1}{1.0} \frac{2}{1.0} \\
\frac{3}{1.0} \frac{4}{1.0 .} \\
\frac{1.0}{1.0}\end{array}$ & $\begin{array}{l}\frac{1}{0.0} \frac{2}{0.0} \frac{\text { Avg. }}{0.0} \\
\frac{3.0}{0.0} \frac{\frac{4}{0.0}}{0.0}\end{array}$ & $\begin{array}{l}\frac{1}{0.0} \frac{2}{0.0} \cdot \frac{A v g .}{0.0} \\
\frac{3}{0.0} \frac{5}{0.0} \\
\frac{0.0}{0.0}\end{array}$ & $\begin{array}{l}\frac{1}{1.0} \frac{2}{0.5} \frac{\text { Avg. }}{0.5} \\
\frac{3}{0.5} \frac{\frac{4}{0.5}}{0.5} \\
\frac{5.5}{0.5}\end{array}$ & $\begin{array}{l}\frac{1}{1.0} \frac{2}{\frac{3}{1.0}} \frac{\text { Avg. }}{1.0} \\
\frac{1}{1.0} \frac{5}{1.0} \\
\frac{1.0}{1.0}\end{array}$ & $\begin{array}{c}\frac{1}{0.0} \frac{2}{0.0} \text { Avg. } \\
\frac{3}{0.0} \frac{4}{0.0} \\
\frac{5}{0.0}\end{array}$ & $\begin{array}{l}\frac{1}{0.0} \frac{2}{0.0} \text { Avg. } \\
\frac{3}{0.0} \frac{4}{0.0} \\
\frac{5}{0.0}\end{array}$ \\
\hline
\end{tabular}


APPENDIX A-11 
Units of Tooth Movements With Facebows of Nine Degrees Torque and Four Ounce Elastics

\begin{tabular}{|c|c|c|c|c|c|c|c|c|}
\hline & $\begin{array}{l}\text { Buccal Tippong } \\
\text { Mex, Rt. }\end{array}$ & 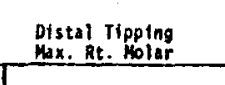 & Max. Rt. & 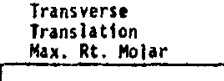 & 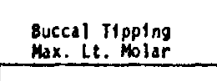 & $\begin{array}{l}\text { oistal Ijpping } \\
\text { Max. Lt. Hetalar }\end{array}$ & & \\
\hline & $\begin{array}{l}\frac{1}{0.0} \frac{2}{0.0} \frac{\text { Avg. }}{0.0} \\
\frac{3}{0.0} \frac{\frac{i}{0.0}}{0.0} \\
\frac{0}{0.0}\end{array}$ & $\begin{array}{l}\frac{1}{0.5} \frac{2}{\frac{1}{1.0}} \\
\frac{3 v g .}{0.9} \\
\frac{1}{1.0} \\
\frac{5}{1.0}\end{array}$ & $\begin{array}{l}\frac{1}{0.5} \frac{2}{\frac{3}{1.0}} \\
\frac{1.0 \text { Avg. }}{1.0} \frac{\frac{5}{1.0}}{\frac{1.0}{1.0}}\end{array}$ & $\frac{\frac{1}{1.0}}{\frac{3}{1.0}} \frac{\frac{2}{1.0}}{\frac{5}{1.0}} \frac{\text { Avg. }}{1.0}$ & $\frac{1}{\frac{0.0}{0.0} \frac{5}{\frac{5}{0.0}} \frac{\frac{2}{0.0}}{0.0}}$ & $\begin{array}{l}\frac{1}{0.5} \frac{2}{1.0} \frac{A v g}{0.9} \\
\frac{3}{1.0} \frac{4}{1.0} \\
\frac{5}{1.0}\end{array}$ & 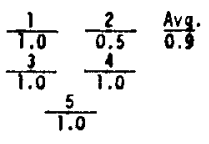 & $\frac{\frac{1}{0.5}}{\frac{3}{\frac{3}{1.0}} \frac{\frac{2}{1.0}}{\frac{4}{1.0}}} \frac{\frac{\text { Avg. }}{0.9}}{\frac{5}{1.0}}$ \\
\hline & $\mid \begin{array}{lll}\frac{1}{0.0} & \frac{2}{0.0} & \text { Avg. } \\
\frac{0.0}{0.0} & \frac{.}{0.0} \\
\frac{5}{0.0} & \frac{5}{0.0}\end{array}$ & 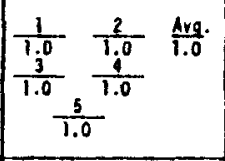 & $\begin{array}{l}\frac{1}{1.0} \frac{\frac{2}{1.0}}{\frac{3}{1.0}} \\
\frac{\frac{1}{1.0}}{1.0} \\
\frac{5}{1.0}\end{array}$ & $\begin{array}{l}\frac{1}{\frac{1.0}{\frac{3}{1.0}}} \frac{\frac{2}{0.5}}{\frac{4}{1.5}} \frac{\text { Avg. }}{\frac{1}{1.0}} \\
\frac{1.0}{1.0}\end{array}$ & $\begin{array}{l}\frac{1}{\frac{0.0}{3}} \frac{2}{\frac{j}{0.0}} \frac{\mathrm{Avg} .}{0.0} \\
\frac{0.0}{0.0} \\
\frac{\frac{5}{0.0}}{0.0}\end{array}$ & $\begin{array}{l}\frac{1}{\frac{1}{3}} \frac{2}{0.5} \\
\frac{\text { Avg. }}{0.9} \\
\frac{1.0}{1.0} \\
\frac{5}{1.0} \\
\end{array}$ & $\begin{array}{l}\frac{1}{1.0} \frac{2}{0.5} \\
\frac{\text { Avg. }}{0.0} \\
\frac{5}{1.0} \\
\frac{5}{1.0}\end{array}$ & $\begin{array}{l}\frac{1}{1.0} \frac{2}{\frac{1}{0.5}} \\
\frac{3}{1.0} \frac{\frac{4}{0.9}}{1.0} \\
\frac{5}{1.0}\end{array}$ \\
\hline c & 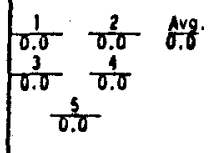 & $\mid \begin{array}{c}\frac{1}{1.0} \frac{2}{1.0} \\
\frac{3}{1.0} \\
\frac{4.9}{1.0 .0} \\
\frac{5}{1.0}\end{array}$ & $\begin{array}{l}\frac{1}{0.5} \frac{2}{\frac{3}{1.0}} \\
\frac{\frac{\mathrm{Avg}}{0.0}}{1.0} \frac{\frac{1}{1.0}}{\frac{5}{1.0}}\end{array}$ & 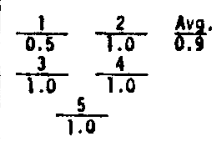 & $\begin{array}{l}\frac{1}{0.0} \frac{2}{0.0} \\
\frac{3}{0.0} \frac{\text { Avg. }}{0.0} \\
\frac{\frac{5}{0.0}}{0.0}\end{array}$ & $\begin{array}{l}\frac{1}{1.0} \frac{2}{1.0} \\
\frac{3}{1.0} \frac{4}{1.0} \cdot \frac{4}{1.0} \\
\frac{5}{1.0}\end{array}$ & $\begin{array}{l}\frac{1}{1.0} \frac{2}{\frac{1.0}{1.0}} \frac{\text { Avg. }}{1.0} \\
\frac{3}{1.0} \frac{\frac{4}{1.0}}{\frac{5}{1.0}}\end{array}$ & $\frac{\frac{1}{1.0} \frac{2}{1.0} \frac{\text { Avg. }}{1.0}}{\frac{3}{1.0}} \frac{\frac{4}{1.0}}{\frac{5}{1.0}}$ \\
\hline 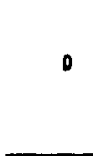 & 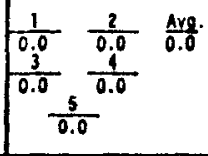 & 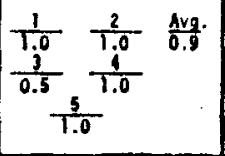 & $\begin{array}{l}\frac{1}{1.0} \frac{2}{\frac{10}{1.0}} \\
\frac{1}{1.0} \frac{1}{1.0} \\
\frac{\frac{5}{1.0}}{1.0}\end{array}$ & $\begin{array}{l}\frac{1}{1.0} \frac{2}{1.0} \\
\frac{3}{1.0} \frac{4}{1.0} \\
\frac{5}{1.0} \\
\frac{5}{1.0}\end{array}$ & $\begin{array}{l}\frac{1}{0.0} \frac{2}{0.0} \\
\frac{3}{0.0 .8} \\
\frac{3}{0.0} \\
\frac{5}{0.0}\end{array}$ & $\begin{array}{l}\frac{1}{0.5} \frac{2}{1.0} \text { Avg. } \\
\frac{3}{1.0} \frac{1}{1.0} \\
\frac{5}{1.0}\end{array}$ & 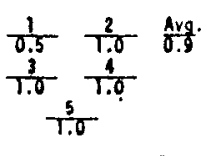 & $\begin{array}{l}\frac{1}{0.5} \frac{\frac{2}{1.0}}{\frac{3}{1.0}} \frac{\frac{1}{1.9}}{1.0 .9} \\
\frac{5}{1.0}\end{array}$ \\
\hline 8 & 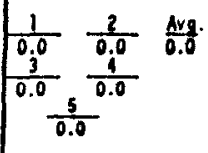 & 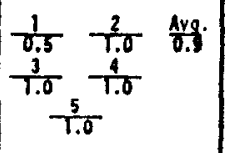 & $\frac{\frac{1}{1.0}}{\frac{3}{1.0}} \frac{\frac{2}{1.0}}{\frac{1}{1.0}} \frac{\frac{A v g}{1.0}}{1.0}$ & 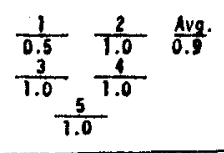 & $\begin{array}{l}\frac{1}{0.0} \frac{2}{0.0} \\
\frac{3}{0.0} \frac{\frac{1}{0.9} .}{0.0} \\
\frac{5}{0.0}\end{array}$ & $\begin{array}{c}\frac{1}{0.5} \frac{2}{7.0} \text { Avg } \\
\frac{3}{1.0} \frac{1.0}{1.0} \\
\frac{5}{1.0}\end{array}$ & 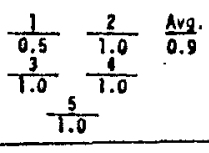 & 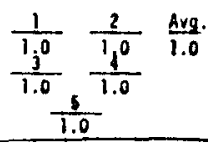 \\
\hline
\end{tabular}


APPENDIX A-12 
Appendix A-12

Units of Tooth Movements With Facebows of Nine Degrees Torque and Six Ounce Elastics

\begin{tabular}{|c|c|c|c|c|c|c|c|c|}
\hline acebour & $\begin{array}{l}\text { Succal Thping } \\
\text { Maxs.Rt. Rollar }\end{array}$ & 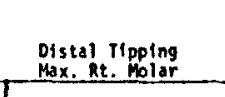 & 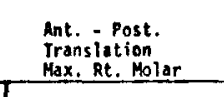 & 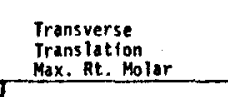 & $\begin{array}{l}\text { Buccal Trpong } \\
\text { Max. Lt. }\end{array}$ & 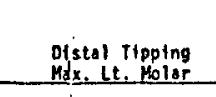 & 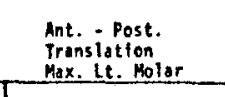 & $\begin{array}{l}\text { Trensuverse } \\
\text { Transflet } \\
\text { Max. Lt. Holar } \\
\end{array}$ \\
\hline A & 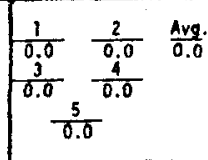 & $\underbrace{\frac{\frac{2}{1.0}}{1.0}}_{\frac{1}{\frac{1}{1.5}}} \frac{\frac{\text { Avg. }}{1.1}}{\frac{5}{1.0}}$ & $\frac{\frac{1}{1.0}}{\frac{1.0}{1.5}} \frac{\frac{2}{1.0}}{\frac{5}{1.0}} \frac{\text { Avg. }}{1.0}$ & $\frac{1}{\frac{1}{1.0}}_{\frac{1}{1.0}}^{\frac{\frac{2}{1.0}}{\frac{1}{1.0}}} \frac{\frac{\mathrm{Avg}}{1.0}}{\frac{1.0}{1.0}}$ & $\begin{array}{l}\frac{1}{0.0} \frac{2}{0.0} \frac{\text { Avg. }}{0.0} \\
\frac{3}{0.0} \frac{\frac{1}{0.0}}{\frac{5}{0.0}} \\
\frac{0.0}{0.0}\end{array}$ & $\begin{array}{l}\frac{1}{1.0} \frac{2}{1.5} \text { Avg. } \\
\frac{3}{1.0} \frac{4}{1.0} \\
\frac{5}{1.0}\end{array}$ & 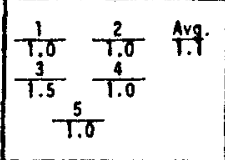 & $\begin{array}{l}\frac{1}{1.0} \frac{2}{0.5} \text { Avy. } \\
\frac{3}{1.0} \frac{1}{1.0} . \\
\frac{5}{1.0}\end{array}$ \\
\hline B & 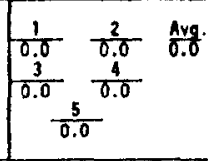 & $\begin{array}{lll}\frac{1}{1.0} & \frac{2}{1.0} & \text { Avg. } \\
\frac{3}{1.0} & \frac{4}{1.0} \\
\frac{5}{1.0} & \end{array}$ & $\frac{\frac{1}{1.0}}{\frac{3}{1.0}} \frac{\frac{2}{1.5}}{\frac{1}{1.0}} \frac{\text { Avg. }}{1.0}$ & $\frac{\frac{1}{1.0}}{\frac{3}{1.0}} \frac{\frac{2}{1.0}}{\frac{4}{1.0}} \frac{\text { Avg. }}{1.0}$ & 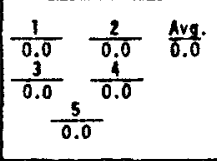 & $\begin{array}{l}\frac{1}{1.0} \frac{2}{1.0} \\
\frac{3}{1.0} \frac{i^{1}}{1.0} \\
\frac{6}{1.0}\end{array}$ & $\begin{array}{ll}\frac{1}{1.0} & \frac{2}{1.0} \\
\frac{3}{1.0} & \frac{4}{1.0} \\
\frac{1.0}{1.0} & \frac{5}{1.0}\end{array}$ & $\begin{array}{l}\frac{1}{1.0} \frac{2}{1.0} \text { Avg. } \\
\frac{3}{1.0} \frac{4}{1.0} \\
\frac{5}{1.0}\end{array}$ \\
\hline c & \begin{tabular}{|lll}
$\frac{1}{0.0}$ & $\frac{2}{0.0}$ & Avg. \\
$\frac{3}{3} .0$ & $\frac{1}{0.0}$ \\
$\frac{0.0}{0.0}$ & $\frac{5}{0.0}$ \\
0
\end{tabular} & 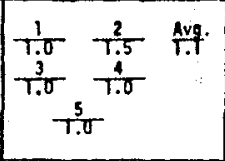 & $\begin{array}{ll}\frac{1}{1.0} & \frac{2}{1.5} \\
\frac{3}{3.5} & \frac{1}{1.09} \\
\frac{5}{1.0} & \\
\frac{5}{1.0} & \end{array}$ & 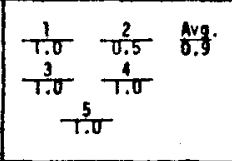 & $\begin{array}{lll}\frac{1}{0.0} & \frac{2}{0.0} & \text { Avg. } \\
\frac{j}{0.0} & \frac{4}{0.0} \\
\frac{5}{0.0} & \end{array}$ & $\frac{\frac{1}{1.0}}{\frac{3}{1.5}} \frac{\frac{2}{1.0}}{\frac{1}{1.0}} \frac{\text { Avg. }}{1.0}$ & 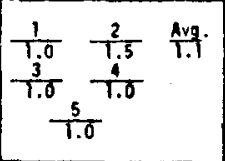 & $\begin{array}{l}\frac{1}{\frac{1.0}{3}} \frac{2}{1.0} \frac{\text { Avg. }}{1.0} \\
\frac{4}{1.0} \frac{5}{1.0} \\
\frac{5}{1.0}\end{array}$ \\
\hline 0 & 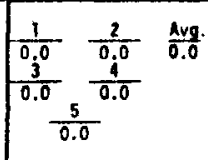 & 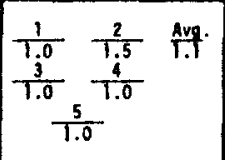 & $\begin{array}{l}\frac{1}{1.0} \frac{2}{1.5} \\
\frac{j}{1.0} \frac{i^{1.0}}{1.0} \\
\frac{5}{1.0}\end{array}$ & 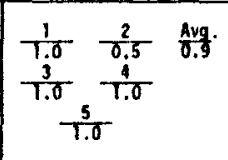 & $\begin{array}{l}\frac{1}{\frac{1}{0.0}} \frac{\frac{2}{0.0}}{\frac{\text { Avg. }}{0.0}} \\
\frac{\frac{4}{0.0}}{0.0} \\
\frac{5}{0.0}\end{array}$ & $\begin{array}{l}\frac{1}{1.5} \frac{2}{1.0} \text { Avg. } \\
\frac{3}{1.0} \frac{1}{1.0} \\
\frac{3}{1.0}\end{array}$ & $\begin{array}{l}\frac{1}{1.0} \frac{2}{1.5} \text { Av9. } \\
\frac{1}{1.0} \frac{1}{1.0} \\
\frac{5}{1.0}\end{array}$ & $\begin{array}{l}\frac{1}{1.0} \frac{2}{1.0} \text { Avg. } \\
\frac{j}{j} \frac{i}{1.0} \\
\frac{1}{0.5} \frac{5}{1.0} \\
\frac{1.0}{1.0}\end{array}$ \\
\hline E & $\begin{array}{l}\frac{1}{0.0} \frac{2}{0.9} \frac{\text { Avg. }}{0.0} \\
\frac{0.0}{0.0 .0} \\
\frac{5}{0.0}\end{array}$ & $\mid \begin{array}{l}\frac{1}{1.5} \frac{2}{1.0} \frac{A v g}{1.1} \\
\frac{3}{1.0} \frac{4}{1.0} \\
\frac{1.0}{1.0}\end{array}$ & $\begin{array}{l}\frac{1}{1.5} \frac{2}{1.0} \frac{\text { Avg. }}{1.1} \\
\frac{3}{1.0} \frac{\frac{6}{1.0}}{1.0}\end{array}$ & $\begin{array}{l}\frac{1}{1.0} \frac{2}{0.5} \frac{\text { Avg. }}{0.9} \\
\frac{3}{1.0} \frac{\frac{4}{1.0}}{1.0} \\
\frac{1.0}{1.0}\end{array}$ & $\begin{array}{l}\frac{1}{0.0} \frac{2}{0.0} \frac{\text { Avg. }}{0.0} \\
\frac{3}{0.0} \frac{\frac{1}{0.0}}{0.0} \\
\frac{5}{0.0}\end{array}$ & $\frac{\frac{1}{1.0}}{\frac{3}{1.0} \frac{\frac{2}{1.5}}{\frac{1}{1.0}}} \frac{\text { Avg. }}{\frac{1.0}{1.0}}$ & $\begin{array}{l}\frac{1}{1.0} \frac{2}{1.0} \\
\frac{10 \mathrm{vg}}{1.0} \\
\frac{1}{1.0} \frac{\frac{1}{1.0}}{1.0}\end{array}$ & $\frac{\frac{1}{\frac{1.0}{3}}}{\frac{1.0}{1.0}} \frac{\frac{2}{1.0}}{\frac{1}{1.0}} \frac{\text { Avg. }}{1.0}$ \\
\hline
\end{tabular}


APPENDIX A-13 
T-comparisons of Non-torqued Facebows for Various Magnitudes of Force for Buccal and Distal Tipping, Anterior-Posterior and Transverse Translation of Maxillary Right and Left Molar.

\begin{tabular}{|c|c|c|c|c|}
\hline Tooth movement & $d f$ & $\begin{array}{l}\text { two ounce vs. } \\
\text { four ounce }\end{array}$ & $\begin{array}{l}\text { two ounce } v \\
\text { six ounce }\end{array}$ & $\begin{array}{l}\text { four ounce vs } \\
\text { six ounce }\end{array}$ \\
\hline $\begin{array}{l}\text { Buccal Tipping } \\
\text { Max. rt. molar }\end{array}$ & 9 & $2.7^{\star}$ & $8.7^{\star \star}$ & $14.0 * *$ \\
\hline $\begin{array}{l}\text { Distal Tipping } \\
\text { Max. rt. molar }\end{array}$ & 9 & $3.1 *$ & $3.0^{*}$ & .8 \\
\hline $\begin{array}{l}\text { Ant. - Post. } \\
\text { Translation } \\
\text { Max. rt. molar }\end{array}$ & 9 & $17.5^{*}$ & $29.7 * \star$ & $15.4^{* \star}$ \\
\hline $\begin{array}{l}\text { Transverse } \\
\text { Translation } \\
\text { Max. rt. molar }\end{array}$ & 9 & 0.0 & 0.0 & 0.0 \\
\hline $\begin{array}{l}\text { Buccal Tipping } \\
\text { Max. it. molar }\end{array}$ & 9 & $3.2^{\star}$ & $10.9 * *$ & $13.3^{* \star}$ \\
\hline $\begin{array}{l}\text { Distal Tipping } \\
\text { Max. it. molar }\end{array}$ & 9 & $2.3^{*}$ & $2.5^{*}$ & .6 \\
\hline $\begin{array}{l}\text { Ant. - Post. } \\
\text { Translation } \\
\text { Max. 1t. molar }\end{array}$ & 9 & $16.5^{\star *}$ & $31.0 * \star$ & $14.6 * *$ \\
\hline $\begin{array}{l}\text { Transverse } \\
\text { Translation } \\
\text { Max. it. molar }\end{array}$ & 9 & 0.0 & 0.0 & 0.0 \\
\hline
\end{tabular}


APPENDIX A-14 
T-comparisons of Torqued Facebows for Various Magnitudes of Force for Buccal and Distal Tipping, Anterior-Posterior and Transverse Translation of Maxillary Right and Left Molar.

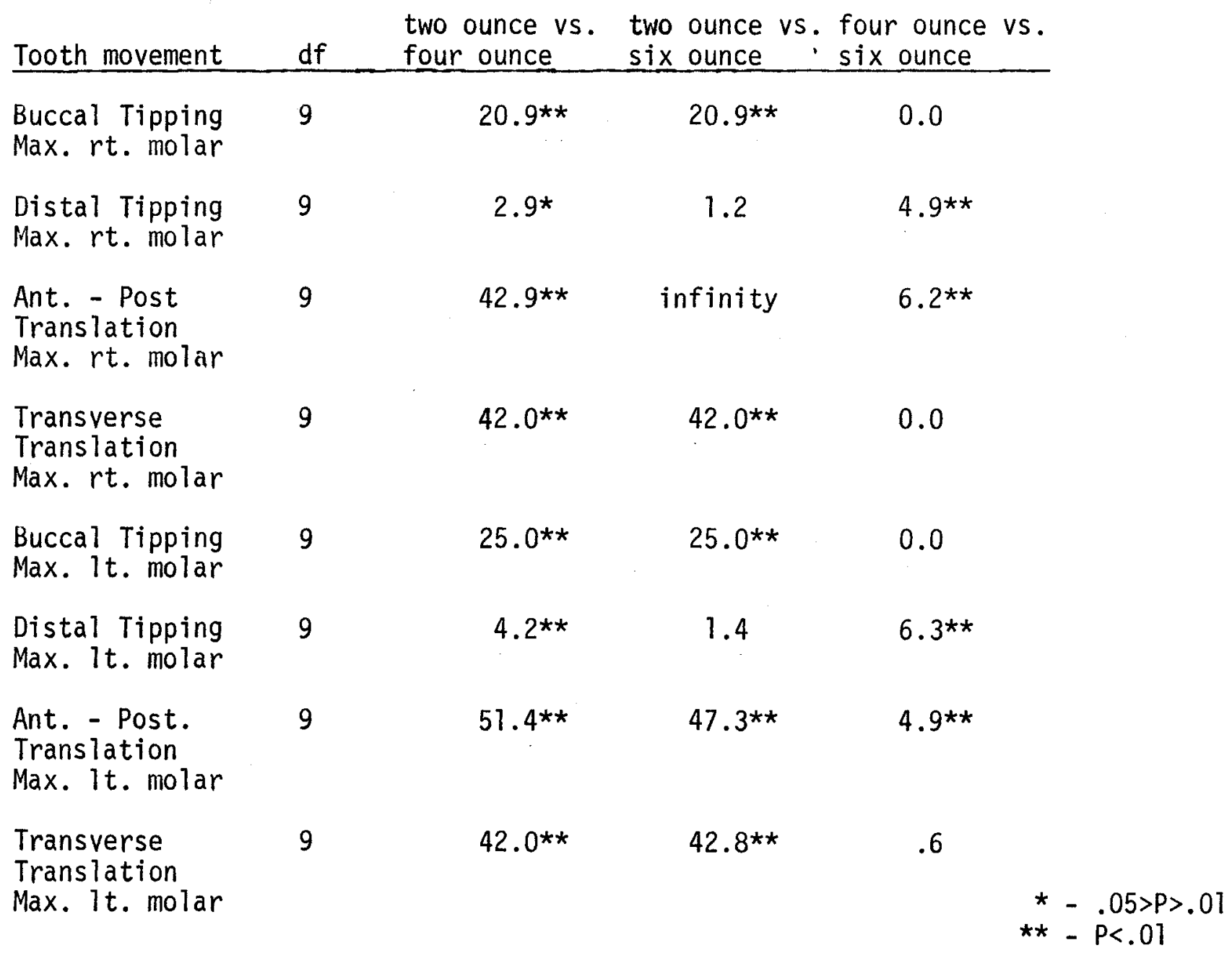




\title{
APPROVAL SHEET
}

The thesis submitted by John $W$. Tabash has been read and approved by the following committee:

\author{
James L. Sandrik, Ph.D., Director \\ Professor, Dental Materials, Loyola \\ Douglas Bowman, Ph.D. \\ Professor, Physiology and Pharmacology \\ Loyola \\ Lewis Klapper, D.M.D., M.Sc., D. Sc. \\ Associate Professor, Orthodontics, Loyola \\ Richard L. Lang, D.D.S., M.S. \\ Clinical Instructor, Orthodontics \\ Loyola
}

The final copies have been examined by the director of the thesis and the signature which appears below verifies the fact that any necessary changes have been incorporated and that the thesis is now given final approval by the Committee with reference to content and form.

The thesis is therefore accepted in partial fulfillment of the requirements for the degree of Master of Science in Oral Biology.
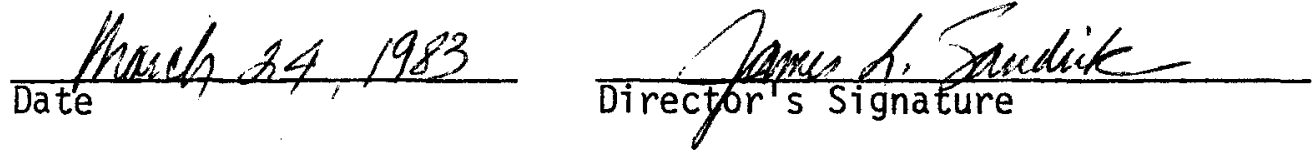